EGCWID-10360

DE92 019690

\title{
Fugitive Dust Control Experiments Using Directed Airflow in Dumping Operations
}

\author{
M. R. Winberg \\ D. E. Menkhaus \\ D. N. Thompson \\ V. E. Wixom
}

Published July 1992

\author{
Idaho National Engineering Laboratory \\ EG\&G Idaho, Inc. \\ Idaho Falls, Idaho 83415
}

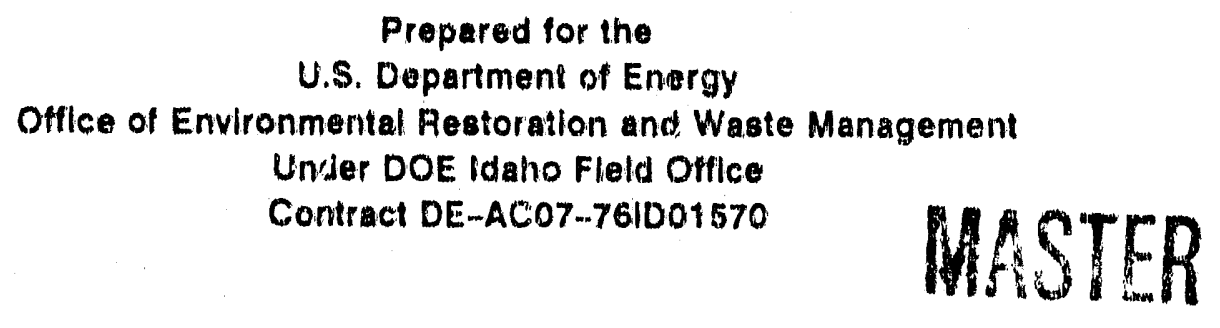


Fugitive Dust Control Experiments Using Directed Airflow in Dumping Operations EGG-WTD-10360

Approved by:

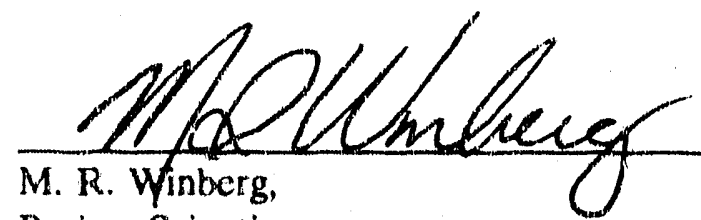

Project Scientist

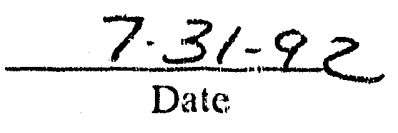

g

K. L. Martin, Unit Manager Nuclear Sciences
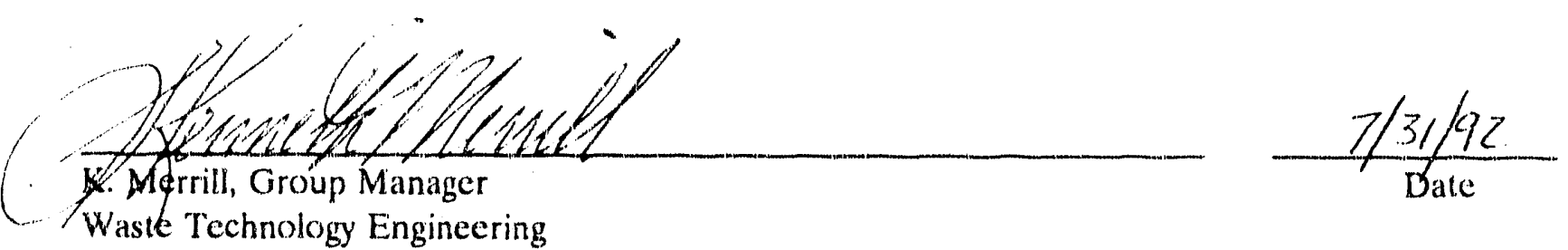

Reviewed by:

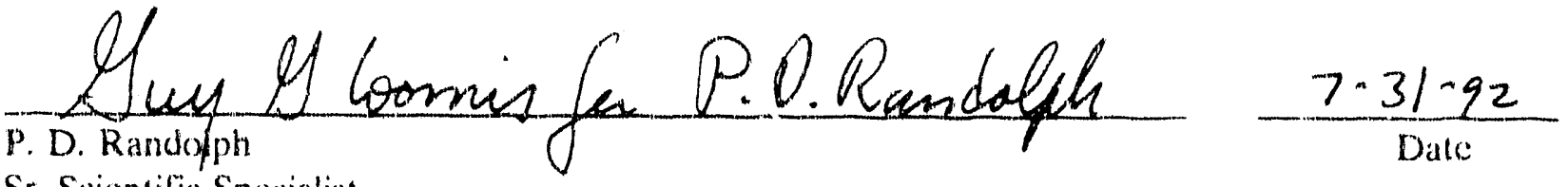
Sr. Scientific Specialist 


\begin{abstract}
Experiments were conducted to evaluate the degree of dust control for using dirccted airflow in a funnel during dumping operations. Retrieved buried transuranic waste or overburden soils are expected to require focusing the retrieved material into a transporter box with a funnel and control of transuranic-contaminated dust at the funnel is mandatory. In these experiments, the ldaho National Engineering Laboratory soil was dumped into a full-scale funnel (capable of focusing waste into a $4 \times 4 \times 8 \mathrm{ft}$ box) that was specially equipped with a directed airflow into the funncl. The degree of dust control was determined by comparing collected dust on filters in high volume samplers (strategically located) for a baseline case with no airflow to cases with airflow. Tests involving airflow into the funnel spanned a range of airflows at the opening between 15-100 linear feet per minute. The basic result is that the directed airfiow concept is adequate 10 control dust spread during dumping.
\end{abstract}




\section{EXECUTIVE SUMMARY}

This report details resulis of tests designed to prove the feasibility of using directed ventilation and airflow to control the generation and spread of fugitive dusts during simulated soil dumping operations. These tests are part of an overall testing program designed to provide information for a contamination control system for use in the retrieval and handling of buried transuranic (TRU) wastes.

During FY-89 to FY-90 a series of tests was performed for the Waste Technology Development Department (WTDD) of EG\&G Idaho, Inc., by EG\&G Nuclear Sciences to determine the feasibility of using a contamination control system to control the generation and subsequent spread of TRUcontaminated dusts during waste retrieval and handling operations. This contamination control system utilized soil fixatives, dust suppression agents, and low-volume liquid misting systems. During these studies it was determined that the low-volume misting system was inadequate in controlling the generation and spread of dusts during simulated soil dumping operations at low soil moisture contents ( $<5 \%$ by mass). For these tests control efficiencies, on the order of $30 \%$ were obtained where control efficiency was the percentage of dust removed when compared to the no misting case. It was then decided to try a new approach to controlling dusts during these types of operations. This approach was to modify the funnel used during the misting system tests to include a directed airflow hood with an attached ventilation system. It was further decided to design the funnel for an expected dumping operation during Transuranic Storage Area (TSA) overburden removal at the INEL's Radioactive Waste Management Complex (RWMC). This design involved a side dump into an opening in a vertical plane. During FY'-91, the new configuration was designed and installed. During FY-92, testing was conducted to determine the leasibility of using this system to control dust generation and provide engineering design information during simulated dry soil dumping operations.

The present tests involved positioning and dumping a $1.25 \mathrm{yd}^{3}$ load of soil inside of the hood opening over the funnel. Air samplers were placed at strategic locations sutside of the funnel which measured the dust concentrations in the air during the dumping operations. Measurements were made with and without the ventilation system in operation using several different flow configurations.

Depending on airflow at the funnel entrance, high control ceficiencics were obtained with the directed airllow apparatus. For cases with 15 linear feet per minute at the lunnel opening, the control efliciency (percentage of dust removed when compared to the baseline case without airflow) was about $69 \%$. For cases where the airllow was near 100 linear feet per minute, collection efficiencies exeecded $98 \%$. This control elficiency in the high llow case (98\%) is higher than for the misting case from previous tests (30\%). However, a direcl eomparison is not possible becausc of extensive design changes to the funnel. The flow area for dust spread was a factor of 3 higher for the lests with the misting system and was oriented facing up, whereas the opening for the airflow ease was in a vertical plane. Since clean uncontaminated soil was used for these lests, no attempt was made to evaluate the actual reduction in spread of contaminants; however, a $98 \%$ decrease in dust spread backed up by other contamination control schemes, such as misting ventilation and vacuuming, is considered adequate. This is because the actual contaminants are expected to be micronsized particles of plutoniumlamericium attached to soils and a $2 \%$ release of the funnel can be handled by other techniques. 
Risults of these tests indicale that the directed airllow system can be used fo eontrol the gencration and spread of TRU-contaminated dusts during dumping operations. Applications of this lechnique could include the removal of soil overburden over drums on pads at the Transuranic Storage Area and removal of soil and huried wastes which are intermingled in pits at the Subsurface Dispesal Arca (SDA). 


\section{CONTENTS}

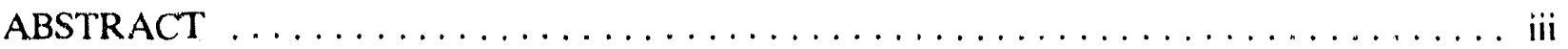

FXECUTIVE SUMMARY $\ldots \ldots \ldots \ldots \ldots \ldots \ldots \ldots \ldots \ldots \ldots \ldots \ldots$

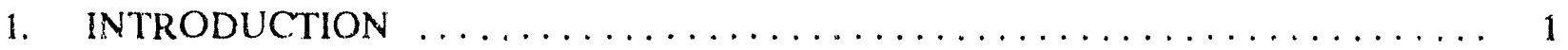

2. BACKGROUND $\ldots \ldots \ldots \ldots \ldots \ldots \ldots \ldots \ldots \ldots \ldots \ldots \ldots \ldots \ldots \ldots$

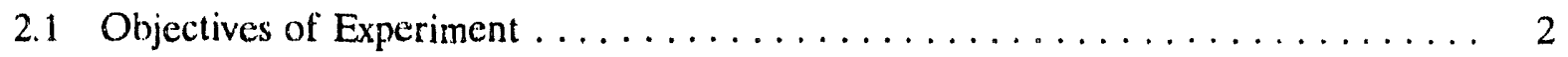

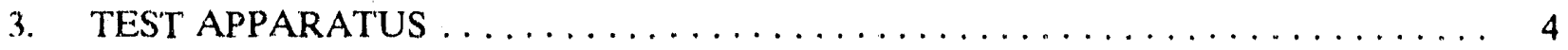

4. TEST METHODS $\ldots \ldots \ldots \ldots \ldots \ldots \ldots \ldots \ldots \ldots \ldots \ldots \ldots \ldots \ldots \ldots$

5. TEST RESULTS $\ldots \ldots \ldots \ldots \ldots \ldots \ldots \ldots \ldots \ldots \ldots \ldots \ldots \ldots \ldots$

5.1 Hood Face Velocity Results $\ldots \ldots \ldots \ldots \ldots \ldots \ldots \ldots \ldots \ldots \ldots \ldots$

5.2 Actual Flow Rate and Average Air Velocity Results . . . . . . . . . . . . 17

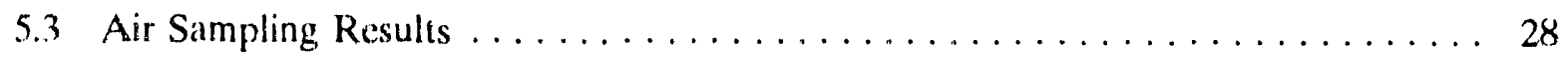

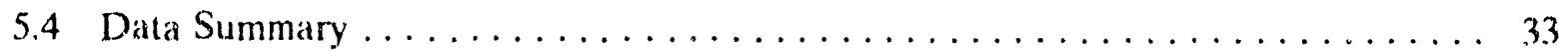

6. CONCLUSIONS AND RECOMMENDATIONS $\ldots \ldots \ldots \ldots \ldots \ldots \ldots \ldots$

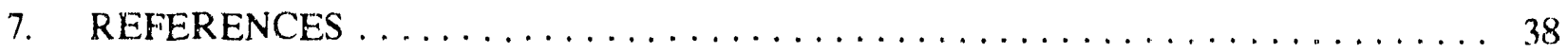

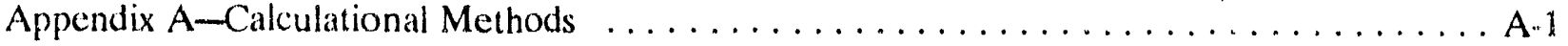

FIGURES

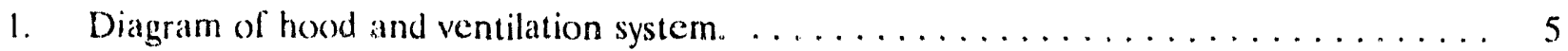

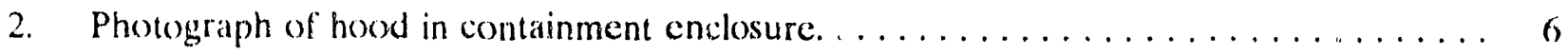

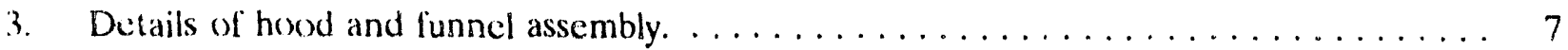

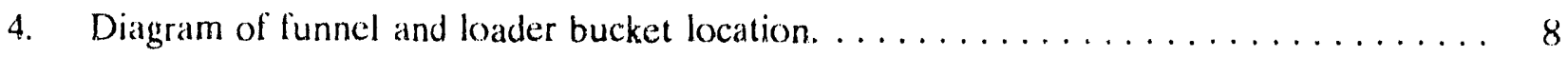

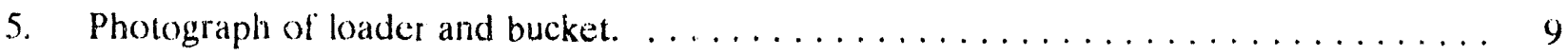

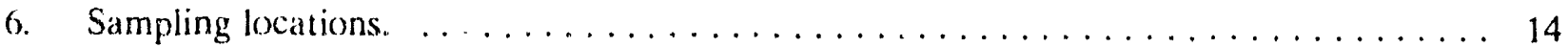




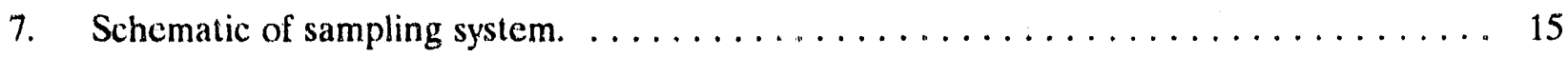

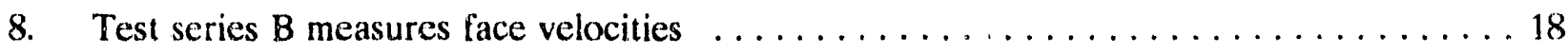

9. Test series $\mathrm{C}$ mear ured face velocities. $\ldots \ldots \ldots \ldots \ldots \ldots \ldots \ldots \ldots \ldots \ldots$

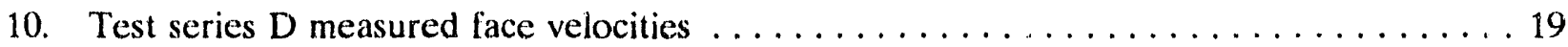

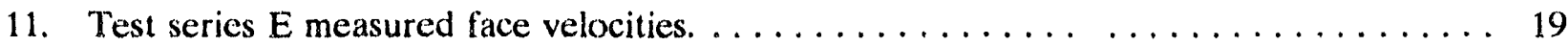

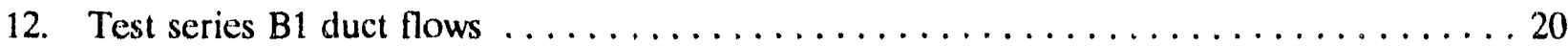

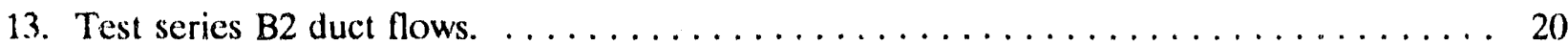

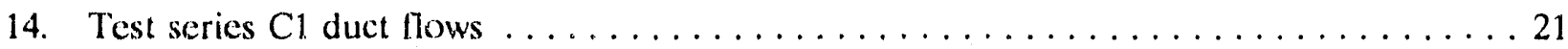

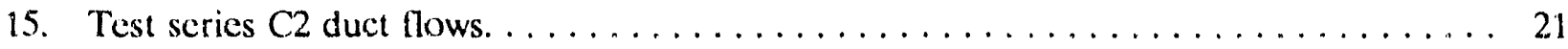

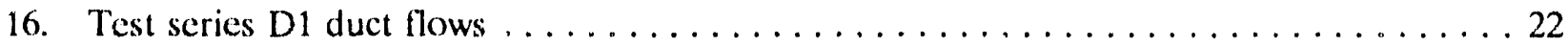

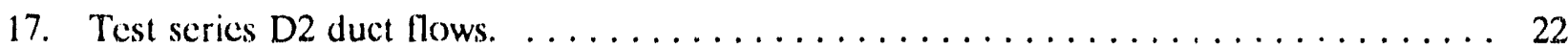

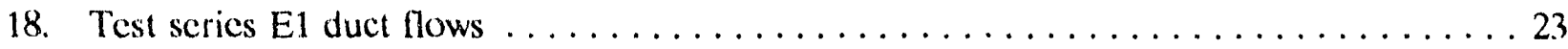

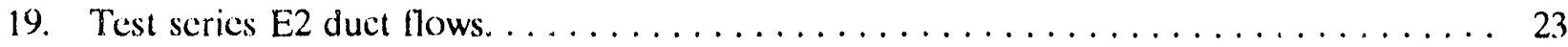

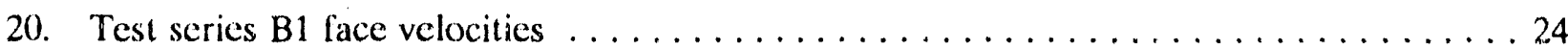

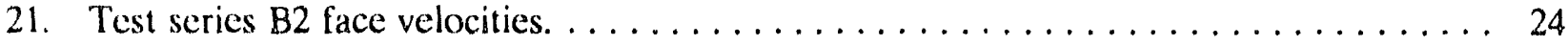

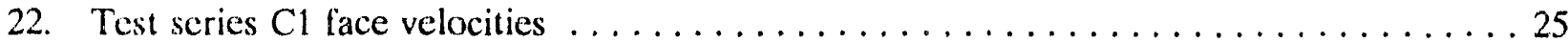

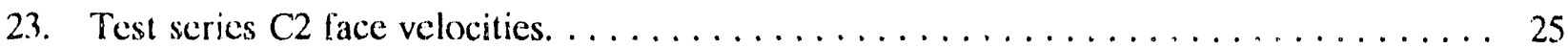

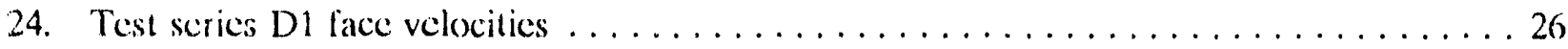

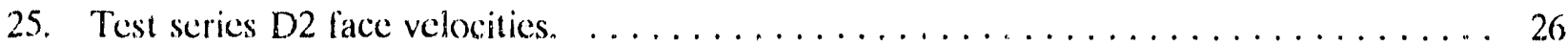

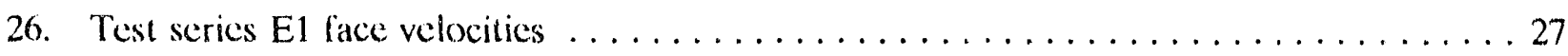

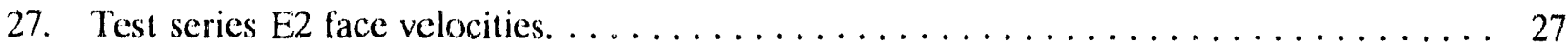

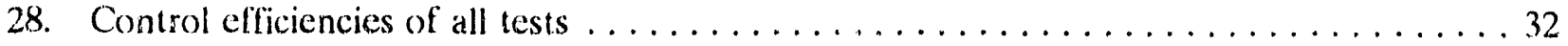

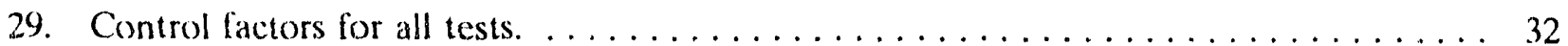

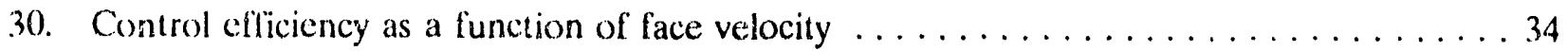


31. Control efficiency as a function of mass flow.

\section{TABLES}

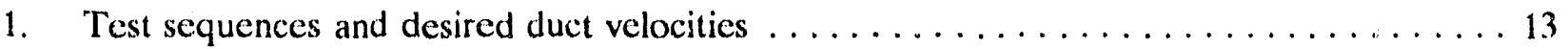

2. Mcasured duct velocity compared to desired duct velocity. . . . . . . . . . . 28

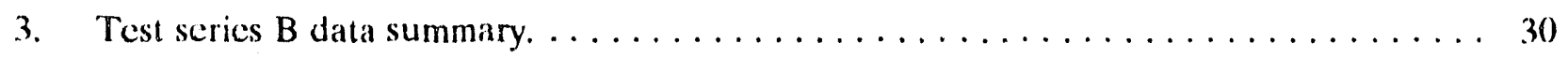

4. Test scries $C$ data summary. . . . . . . . . . . . . .

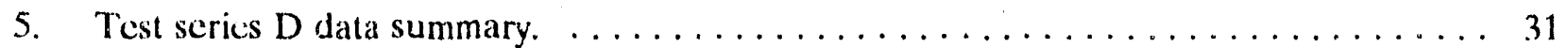

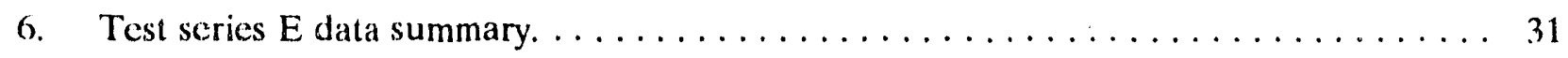

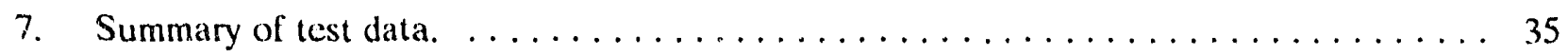




\section{Fugitive Dust Control Experiments Using Directed Airflow in Dumping Operations}

\section{INTRODUCTION}

This report details results of tests designed to prove the feasibility of using directed airflow to control the generation and spread of lugitive dusts during simulated soil dumping operations into a funnel. These tests are part of an overall testing program designed to provide information for a contamination control system for use in the retrieval and handling of buricd transuranic (TRU) wastes. Methods used to perform these tests we re documented in a test plan and previous studies conducted in this area. ${ }^{1-4}$

This report describes the background information preceding these tests, describes the objectives of the test., describes the test apparatus, outlines the test methods, reports and summarizes results, and gives basic recommendations and conclusions based on the data. 


\section{BACKGROUND}

During the time period from 1950-1972 TRU-conlaminated wastes were received at the Idaho National Engineering Laboratory (INEL) from weapons production acivitics at the Rocky Flats Plant. Most of these wastes were contained in drums and boxes and were buried in shallow landfilled pits and trenches at the Radioactive Waste Management Complex (RWMC). One of the plans for these wastes includes retrieval of the wastes for reprocessing and shipment to a permanent disposal site and remediation of the burial sites. Over the years that these wastes have been buried at the RWMC, it is assumed that the original containers have deteriorated to the point that the waste materials and surrounding soil have intermingled and the soil has been contaminated with TRU elements.

During FY-90, the DRYFOG Ultrasonic Misting Head (manufactured by Sonics Inc.) was evaluated to determine the feasibility of using a low-volume misting system to control fugitive dust spread during large scale simulated retrieval dumping operations. Experiments were conducted using three different soil moisture types: dry (less than $4 \%$ moisture by weight), moist ( $8-10 \%$ moisture by weight), and wet ( $>15 \%$ moisture by weight). Three different misting head configurations were evaluated using each of the different soil types. Tests were performed with and without the misting sysiciii in operation to determine the performance of each misting system configuration. Results indicated that the misting system performed well on wet soil (75 to $92 \%$ control efficiency), less on moist soil (50 to 62\% control efficiency), and poorly on dry soil ( 0 to $32 \%$ control efficiency). A viden of the misting system operation showed that the major reason for the failure of the misting system to control dust generation with dry soil was the displacement of air from the bottom of the funnel during the dumping process. This displacement gave the dust particles upward momentum and allowed them 10 displace and move through the misting curtain.

Retricval designs for overburden on the Transuranic Storage Area (TSA) at the RWMC indicated the possible need for a funnel for dumping overburden into conveyance vehicles. Since the previous dumping results showed that the existing funnel using misting systems appeared inadequate for dust control, it was decided to use directed airflow to control dust. The funnel was modified to reflect a design that could be utilized on the TSA project with a funnel opening in the vertical plane.

Soil core samples taken at the RWMC show an average soil moisture content of $15 \%$ or greater. However, if any dry pockets of soil are encountered during actual retrieval operations, the misting system alone may not be adequate to control dust generation and subsequent contamiration spread beyond the general funnel area. In addition, the weight \% moisture content of the overburden soil covering the waste stored on the RWMC Transuranic Storage Area pads is expected to be less than $5 \%$. Misting for removal of this overburden is expected to be ineffective.

\subsection{Objectives of Experiment}

The experimental objectives are:

- To determine the control efficiency (percentage of dust removed when compared to the bascline no airflow case) of using a local ventilation system at a range of opening velocities from 15-100 lfpm to control the dust generated during dumping operations similar to those 
that would be performed during retrieval of buried waste and during the removal of overburden from the stored waste at the RWMC.

- To provide engineering data for the design of a local ventilation system which will control dust generated during an excavator dumping operation. 


\section{TESTI APPARATUS}

A diagram and a photograph of the funnel and bucket hood arrangement, the wooden box, and the ventilation system are shown in Figures 1-3. The top of the funnel is approximately 9.67 feet above the floor surface. The funnel is $11 \mathrm{ft}$ wide and $9.67 \mathrm{ft}$ deep. The tront surface of the funnel has a $1: 1$ slope $\left(45^{\circ}\right)$ and the back has a $3: 2$ slope ( $56^{\circ}$ with respect to the horizonal). The funnel tapers to a $3 \mathrm{ft}$ by $7 \mathrm{ft}$ throat. The throat is approximately $1 \mathrm{ft}$ long. The bottom of the funnel throat is approximately $4.5 \mathrm{ft}$ above the floor surface. The design of the funnel involved reducing the cross. sectional flow area to maximize the opening fow velocity when the excavation bucket is positioned over the opening.

The bucke hood encloses the furnel on the top and three sides, leaving an opening only on the one side that the bucket enters. Iigure 4 shows the overall dimensions of the hoof an features contained within the hood. On cach inside surface of the hood entrance is an air dam that blocks 15 in. of the entrance area as shown in Figure 3. Louated near the rear of the hood are flow baffles and located on the back wall of the hood is a flo deflector as shown in Figure 3. The purpose of the flow baffes and flow deflector is to help distribute the airflow and, therefore, reduce the air velocity gradients at the entrance of the hood and within the hood. A 3 ft by 4 ft viev port is provided on one side of the hood 10 allow visual observation and video documentation of the dimping experiments. The bucket hood was fabricated from the sketches documented in Reference 4.

The soil is captured in a 4 -ft deep by 8 -ft wide by 4 -ft high dumpster (wooden box). The box used is fabricated per EG\&G drawing 410206 modified by adding inner walls and a cylindrical botion. Details of these modifications are documented in Reference 4. To prevent dust from escaping at the funnel and box interface, a plastic skirt is taped to the funnel and box at this interlace.

A loaderbackhoe with a multi-purpose bucket is used to dump the soil into the funnel. The bucket is 78 inches wide and holds approximately 1 cubic yard of sril. A photograph of the backhoe with a typical load of soil is shown in Figure 5. The general shape of the bucket and its position relative to the funnel with the bucket in the dump position is shown in Figure 4.

The ventilation system is used to provide an inward airflow into the bucket hood. Two branches of ventilation are provided as shown in Figure 1, an upper branch and a lower branch. Both branches join into the main duce that connects to the fan/motor arrangement. The upper branch connects to the back wall of the bucket hood and allows air to be drawn directly through the hood. Flow baffles and air deflector are positioned near the back wall, as shown in Figure 3, to distribute the flow through the hood.

The lower branch duct connects to the outside of the funnel throat. It draws air at sib locations around the perimeter of the throat lunnel (three locations on each of the long sides of the funrel throat) as shown in Figure 3. Additional details of the lower ventilation duciing is docurnented in sketches in Reference 4.

Dust is captured in roughing and high efficiency particulate air (HEPA) filters located upstream of the lan. The fan is driven by a variable speed motor. The variable speed lan along with the flow 


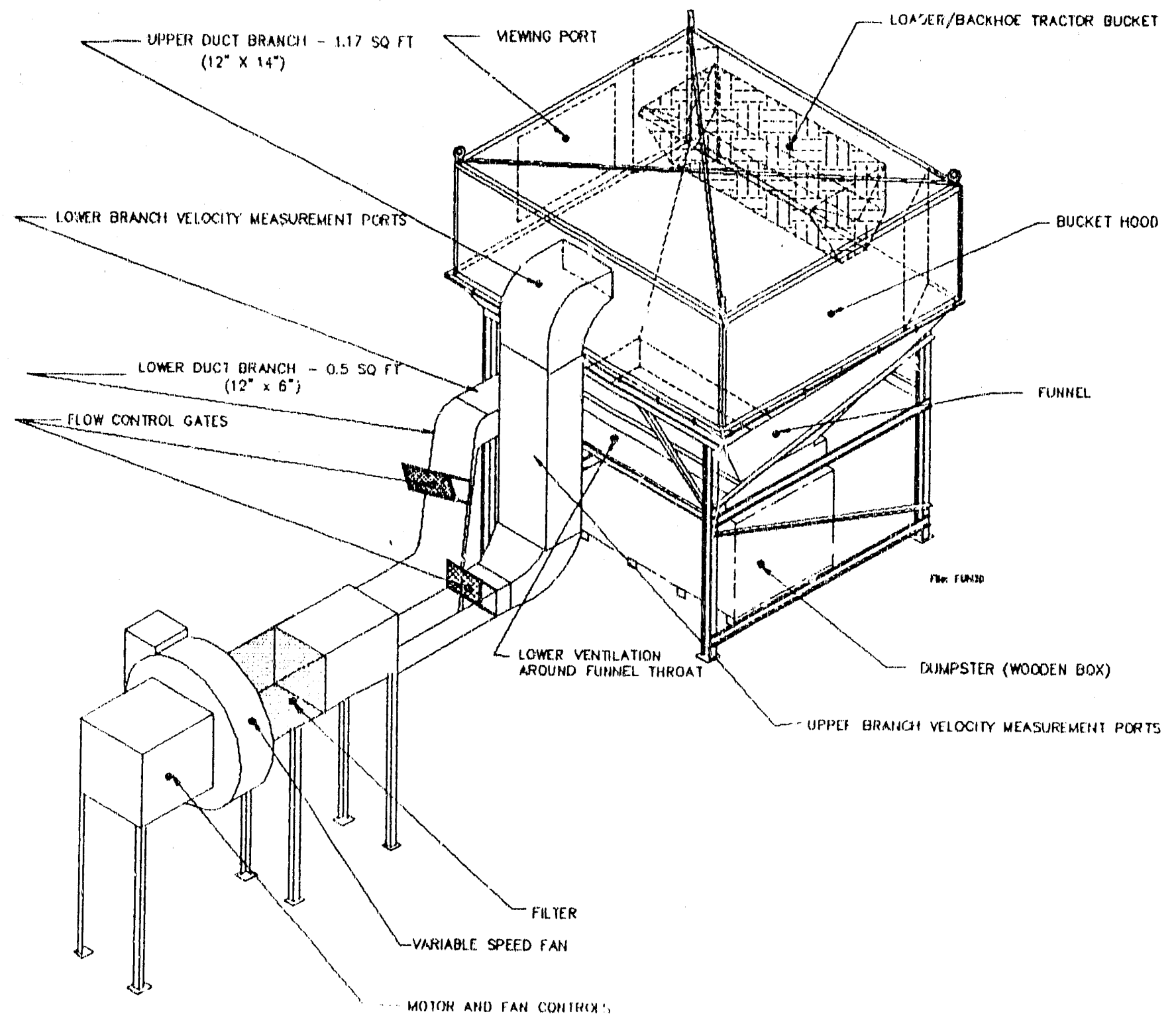

Figure 1. Diagram of hood and ventilation system. 


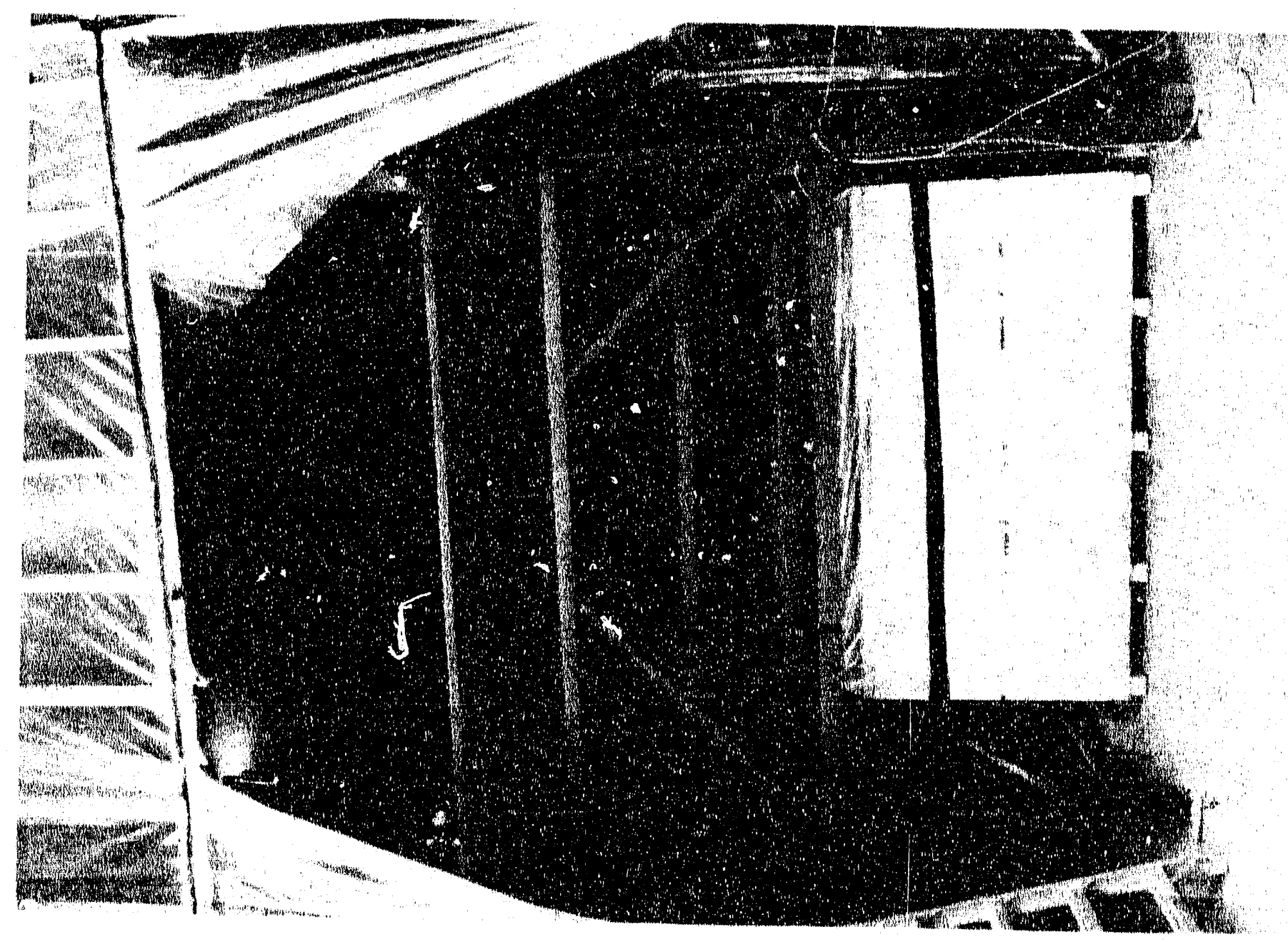

Figure 2. Photograph of hood in containment enclosure. 

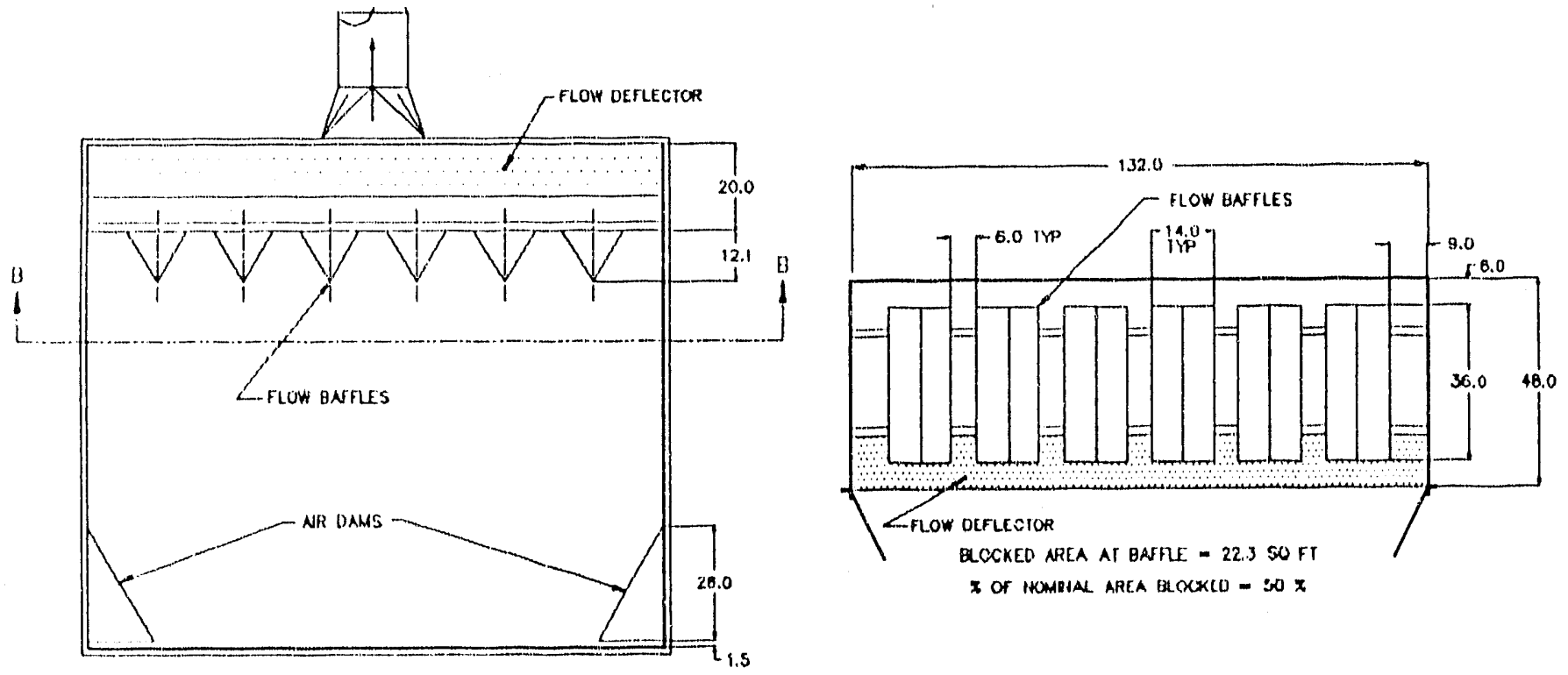

$x$ OF HOMRIAL AREA BLCXKLO $-50 x$

SECTION B-B

SECTION A-A

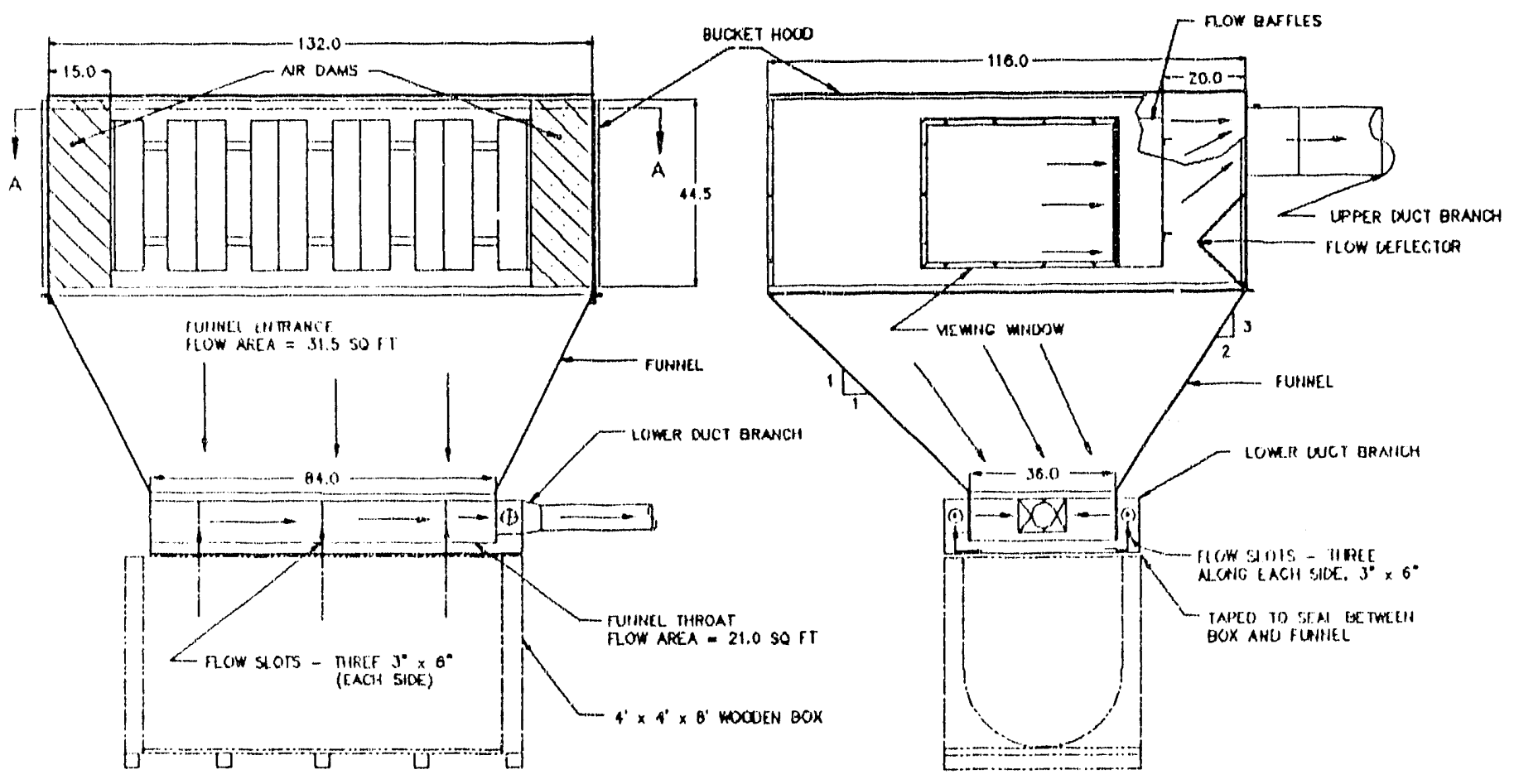

Flla: LUSTAPP

Figure 3. Delails of hood and funnel assembly. 


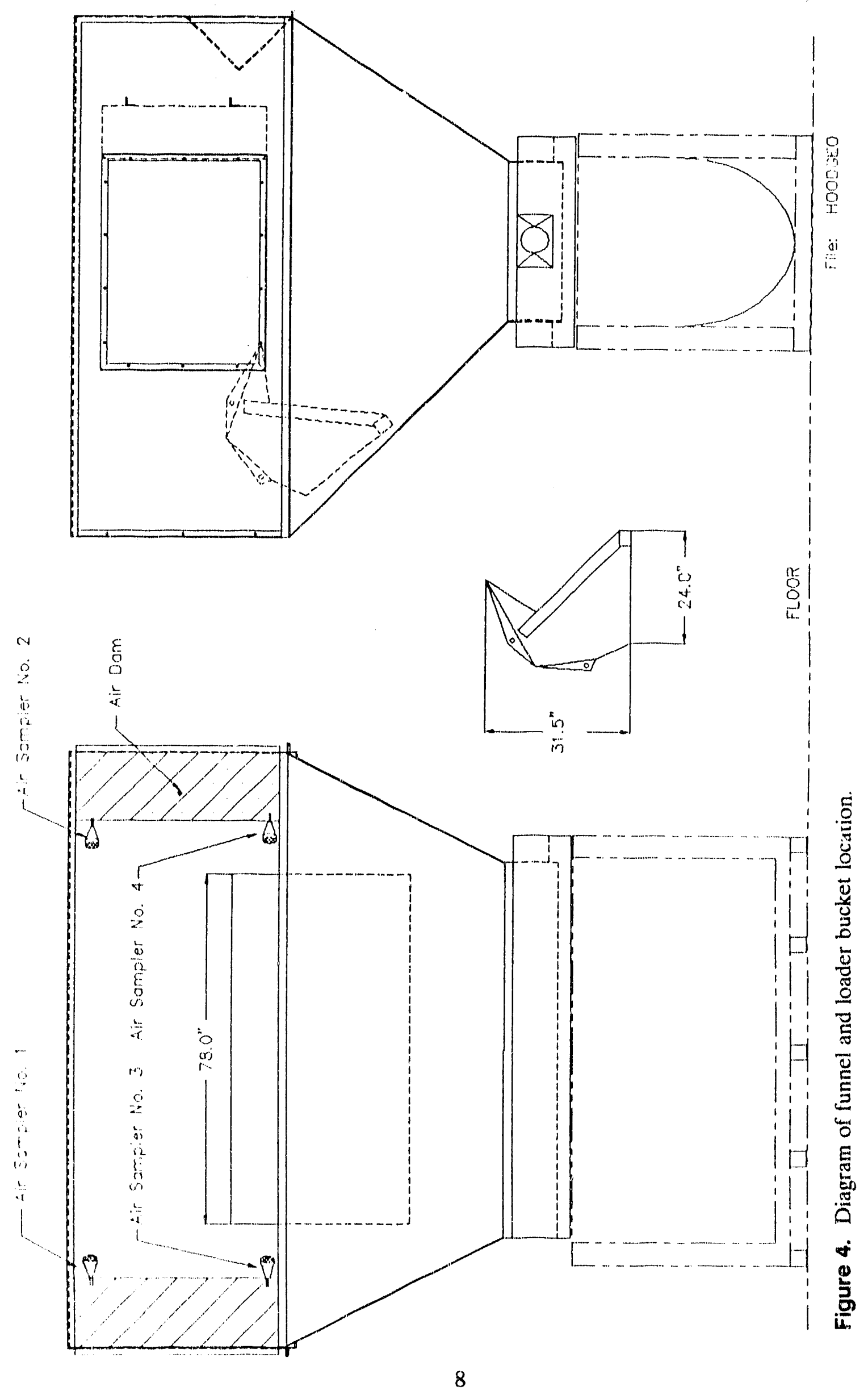




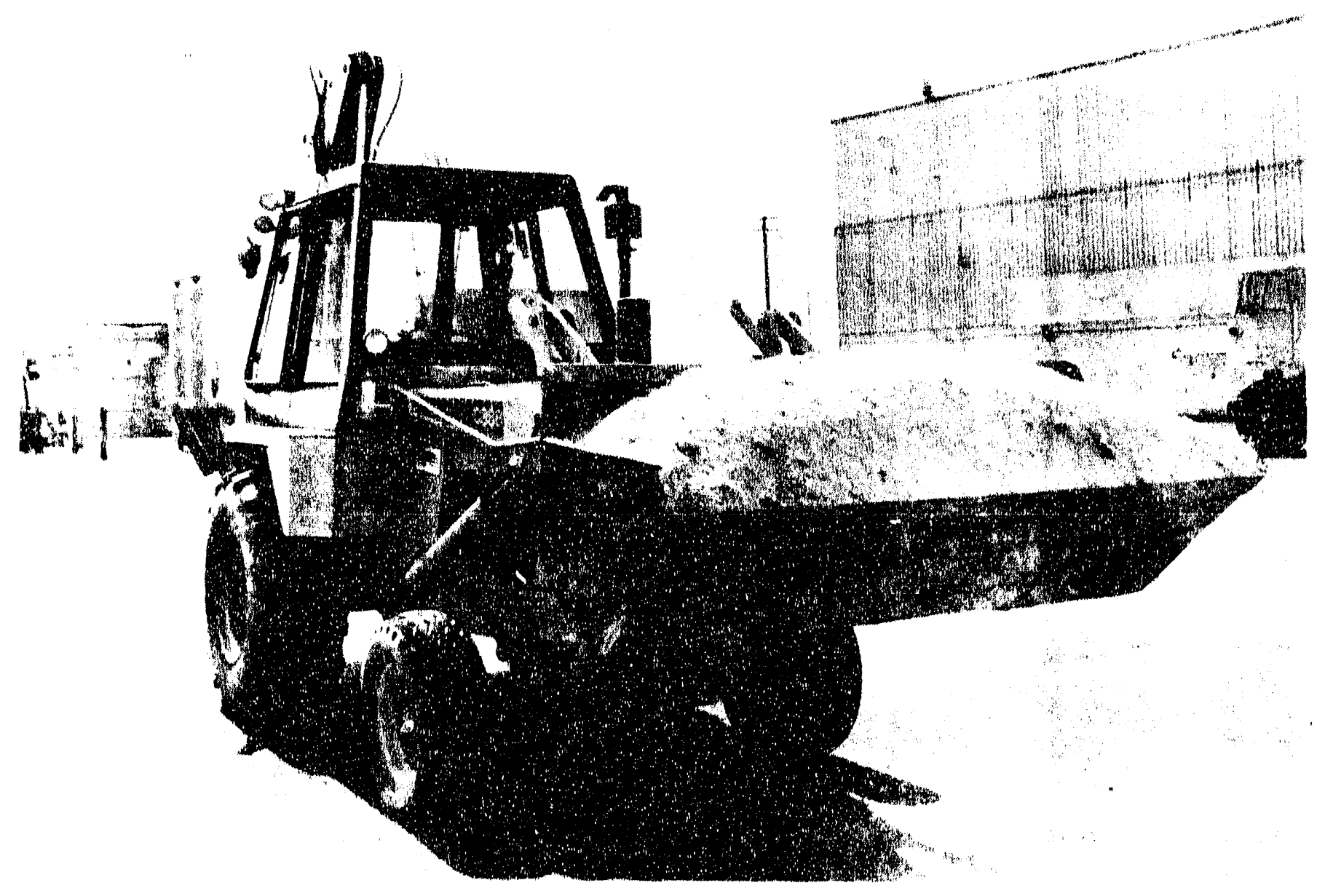

Figure 5. Photograph of loader and bucket. 
control gates in each branch of the ducting are used to establish the flow rate in the upper and lower branches of the duct.

Air velocity measurement ports are provided in the upper and lower ducts to determine air velocities within the ducts. This will provide the information needed to calculate the airflow rates and average air velocities through the ventilation system, funnel, and bucket hood. 


\section{TEST METHODS}

The test sequences were established to obtain a variety of average air velocities through the hood face from airflows through the upper and lower branches of ducts. In addition, the lower duct branch provided a downward air velocity through the throat of the lunnel to provide additional forec to counteract the upward plume of dust resulting from the dirt rapidly displacing the air in the box during the dumping operation.

Test were run with flow through the upper duct branch only (B test serics), the lower cluct branch only ( $C$ test series), and the combination of tlows through both branches ( $D$ test series). In addition, an $\mathrm{E}$ test series was run with the top 12 in. of the hood face blocked with a plastic skirt. This decreased the hood-face flow area, resulting in similar hood face velocities as the D lest series, but at lower total llow rates through the ventilation system. No llow lest runs (A test) were performed to obtain baseline information for comparison with the results from the test series utilizing airllow.

The lower duct branch flow rates were selected to obtain approximately 25 and $50 \mathrm{lfpm}$ through the throat of the funnel. The lower flow branch was included for the following reasons:

- The lower branch flow was designed to augment the upper branch flow to reduce the time to pull the dust down from behind the bucket and, therefore, minimize the amount of dust that would be pulled out of the hood if the bucket was removed shortly after the dump was completed.

- The lower branch flow was designed with flow around the perimeter of the hood throat to achicve an approximately constant air velocity through the funncl throat. This air velocity helped slow down the upward plume of dust from the box resulting from the dumping operation.

- The lower branch flow reduced the time to remove the dust from the lower portion of the funnel after the dump. It was anticipated that the upper branch flow would llow directly from the hood face to the back of the funnel. As a result, the dust in the lower portion of the funnel would require a longer time period to settle if the lower branch flow did not pull the dust from this section of the funnel.

Since the flow through the lower branch was around the bottom of the funnel throat near the soil and around the area of high dust concentrations during the dump operation, high air velocities in this area would carry significant amount of dust through the ventilation system increasing the demands on the air cleaning devices. Therefore, to achieve the objectives stated above at minimal air velocities, it was desirable to minimize the dust carried into the ventilation system.

The primary purposes of the upper branch were to:

- Provide suflicient airllow through the hood to create high enough lace velocity at the hood entrance to contain most of the dust within the hood. 
- Clear the dust from within the hood around the bucket to reduce the amount of dust that would be pulled out of the hood as the bucket was removed from the hood.

- Help minimize the air velocity variations at the hood face. It was anticipated that flow from the lower branch only would create large variations in air velocity at the hood face, resulting in an inefficient overall capture of the dust at the hood face. The higher flow rates from the upper branch would help reduce these velocity variations.

The test sequence values were selected to achieve face velocities at the hood entrance which ranged from low velocities to values greater than $100 \mathrm{fpm}$.

Table 1 summarizes the desired average air velocities through the ducts for the test series sclected. The variable speed fan was used to establish the flow rate. The average velocity through the duct was determined by measuring the velocity profile at 18 locations in the $6 \times 12$ in. duct (lower branch) and 16 locations in the $12 \times 14$ in. duct (upper branch). An iterative process was used to achieve the average air velocities (and therefore the airllow rates) through the duct branches for each test sequences. As seen from Table 1, the test series were established to minimize the number of different average velocities through each duct branch to help minimize this iterative process. Once the duct velocity profiles were determined for each test series, the desired flow rates were reestablished in each duct branch using a single velocity measure at one of the locations in each b. anch where the single point velocity was close to the average velocity and the velocity gradient in the branch was low. The variable speed fan then was adjusted to achieve the approximate desired average duct velocity (and therefore the flow rates to achieve the air velocities in the funnel and hood) by re-establishing the desired single point velocity.

Velocity measurements were perlormed using Omega Model FMA-600 series Air Velocity Transducers (range: $0-2000$ SCFM; accuracy: $\pm 4 \%$; and repeatability: $\pm 0.5 \%$ ). The velocity transducer outputs were connected to a Omega Model 481 datalogger. The output from the datalogger was connected to a Compaq LTE/286 computer which utilizes a custom designed software package to interrogate and store data outputs from the datalogger for further data analysis.

One of the major design parameters for controlling the escape of dust from the hood enclosure was the hood lace air velocity. Although the average face velocity can be calculated from the duct flow rate data, it was also desirable to know the velocity variations at the hood face area. It was advantageous to minimize this velocity variation to achieve a balanced dust control mechanism at the hood entrance--that is, to prevent areas of low hood face velocities which would be less effective in controlling the dust from escaping with respect to the areas of higher face velocities.

Prior to performing the soil dump tests, velocity measurements were made at the hood face. These measurements were performed with the bucket positioned in the hood in its dump position to best reproduce the conditions during the time when the dust needs to be controlled. Note that the velocities at the hood were in the very low range of velocity transducers described above used to perform these measurements and, therefore, do not provide an accurate measure of the velocities. However, the reported repeatability $( \pm 10$ SCFM) of the instruments was sufficiently small to provide reasonable data on the variability of the air velocities at the hood entrance for most of the test series. 
Table 1. Test sequences and desired duct velocities.

Test ID

A1

B1

B2

C1

$\mathrm{C} 2$

D1

D2

$\mathrm{E}^{\mathrm{a}}$

$\mathrm{E} 2^{\mathrm{a}}$
Upper Duct Flow (Ifpm)

$$
0
$$

1000

2000

()

0

1000

2000

770

1000
Lower Duct Flow

(lfpm)

\section{0}

()

0

$10(0)$

2100

2100

2100

1000

2000

a. Upper part of hood opening partially blocked with 12 in. of plastic.

During each soil dumping test run for each of the test sequences, air samples at four locations around the perimeter of the hood entrance were obtained using $47 \mathrm{~mm}$ open-faced particulate samplers. These samplers contained glass fiber HEPA quality particulate lilters. Locations for the samplers are shown in Figure 6. These samplers were connected to McMillan Model 10 or Model 12 mass llow sensors. The output from the mass flow sensor was connected to the datalogger and $\mathrm{PC}$ in the same manner as the velocity transducers. Air movement through the samplers and the mass flow sensors was accomplished using Gast rotary vane vacuum pumps. A schematic of the entire sampling and data acquisition systems is shown in Figure 7.

All equipment requiring calibration was calibrated by the EG\&G Idaho Standards and Calibrations Laboratory to ensure data quality.

All of the soil dumping test runs were performed using RWMC-type soil which contained less than $5 \%$ moisture by weight. The particle size distribution in the RWMC soil has been documented in previous studies. The soil contains a high percentage of very small grain size. This, in addition to low moisture content, results in large quantities of dust being generated during soil retrieval activitics. In addition, the very small dust particles have low settling velocities resulting in the dust drifting in the air for long periods of time before they settle.

Each test sequence was performed three times as follows:

- Weigh eight cach $47 \mathrm{~mm}$ particulate lilters

- Place lilters in filter holders 


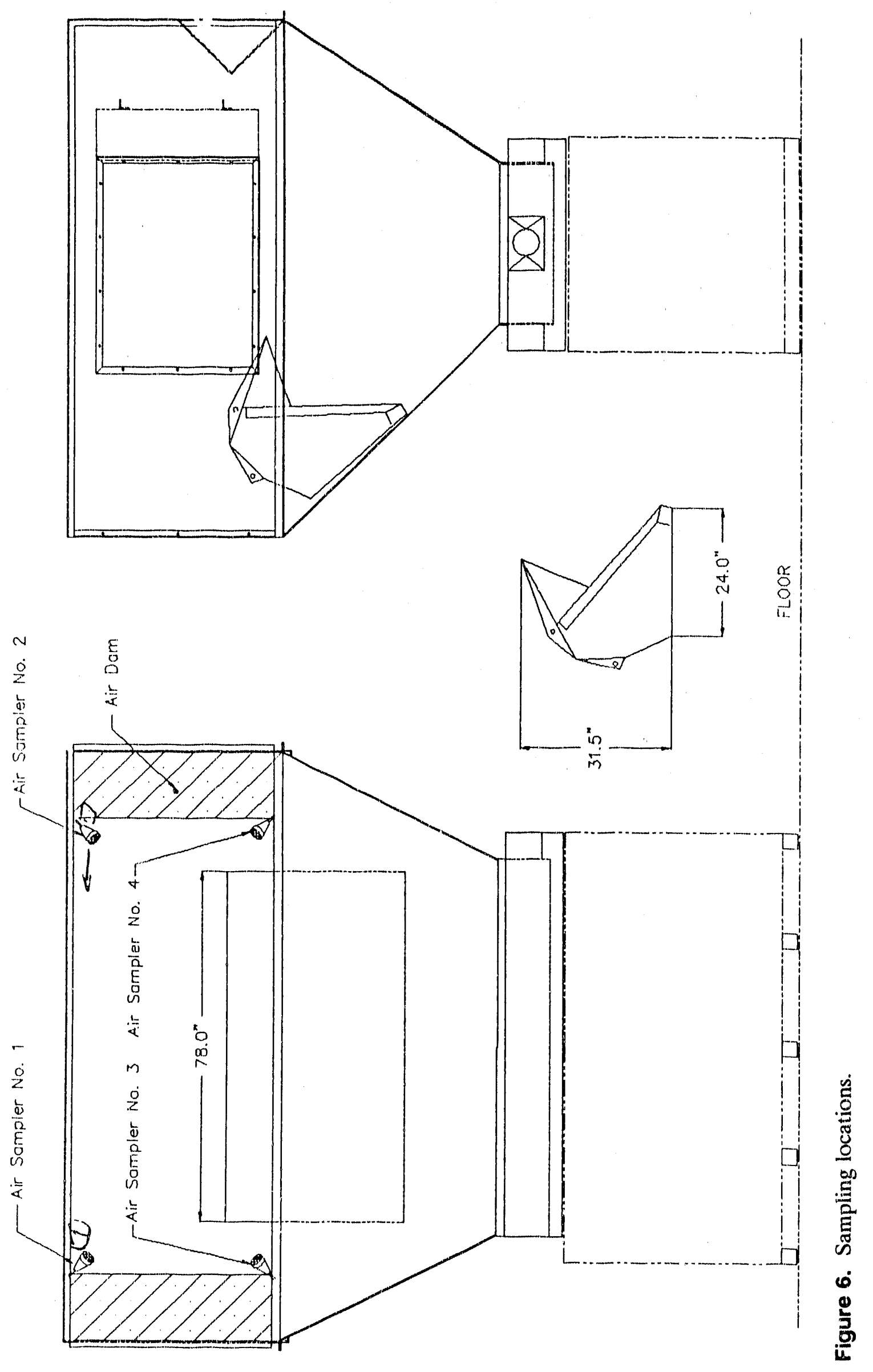


47 MMP P ARTICULATE S AMTPLERS

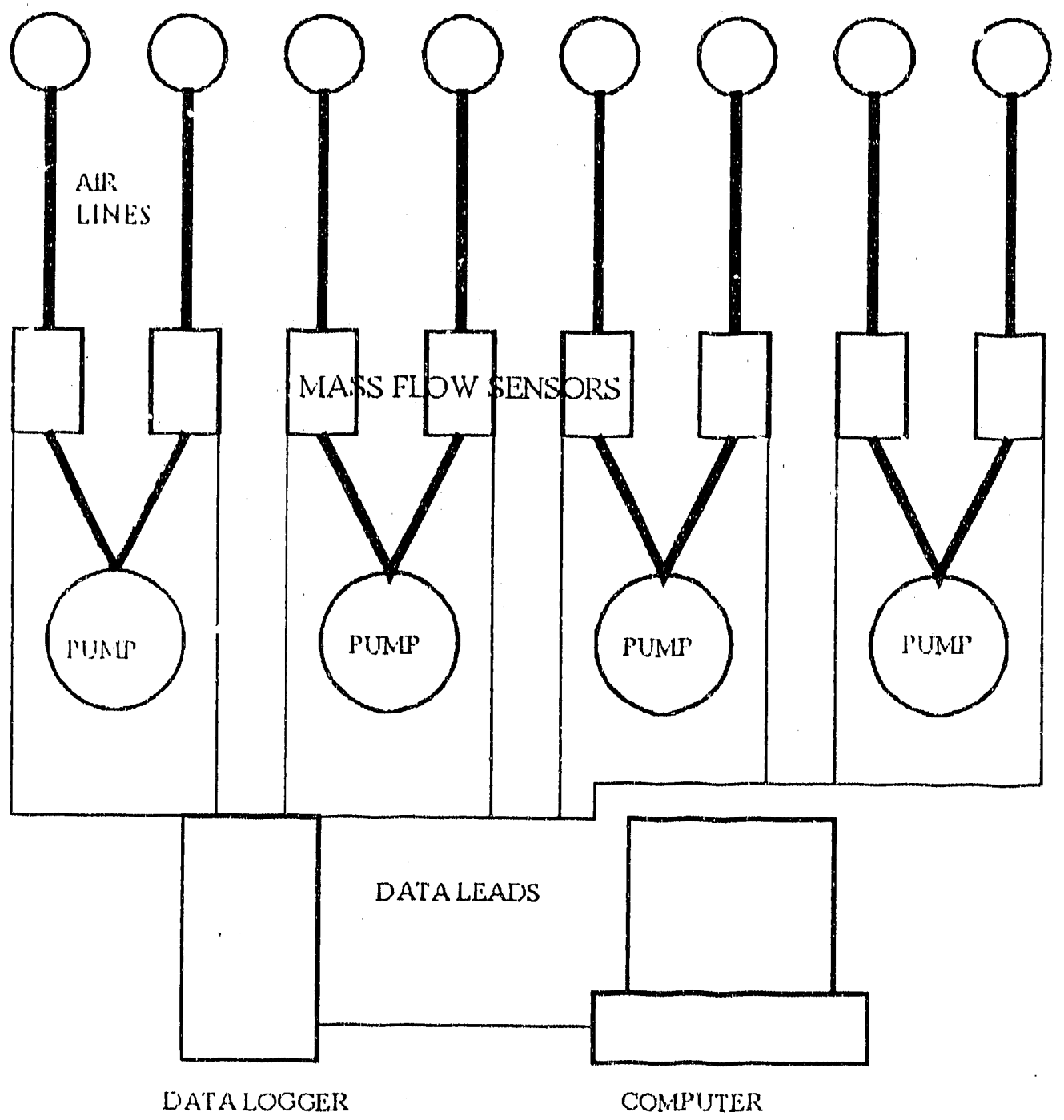

Figure 7. Schematic of sampling system. 
- Place filters in sampling position

- Position loader bucket containing scil in hood opening

- Turn on ventilation fan and sampling pumps

- Begin data logging on PC

- Slowly dump dirt into funnel (approximately 3 seconds to complete dump)

- Run samplers and ventilation fan for 3 minutes after dumping

- Turn off samplers and ventilation system

- End data logging

- Collect filter holders

- Remove and weigh filters.

Data from the datalogger was collected on disk for further analysis. Sample weights and test parameters were recorded iii the project logbook.

Finally, each of the dump test sequences was repeated to obtain documentation photographs and videos of the tests. Videos of the hood entrance and the interior of the hood were made for each dump test series. 


\section{TEST RESULTS}

\subsection{Hood Face Velocity Results}

Approximately 10 velocity measurements at 10 second intervals were made at 18 locations (12 locations for the E test series) for cach test series to measure the velocity variations at the hood face cross-section. The face velocity averaged values along with the averaged value for each row and column of measurements are shown in Figures 8-11. An air velocity instrument to measure the low face velocity values was not available. As a result, the same instruments used to measure the duct velocities was used. The repeatability of the instrument was $\pm 0.5 \%$ FS ( $\pm 10 \mathrm{fpm}$ ). So, some of the velocity trends may be masked within the repeatability of the mcasurements. However, several trends appear to exist:

- The velocity was higher on the top section of the hood face than the lower section. This is probably attributed to the bucket positioned in the hood.

- The velocity was higher on the right side of the hood face than the left side. The upper-left area (A1 location) consistently yielded the lowest velocity values. This may be partially contributed to the lower branch of ducting being attached to the right side of the lunnel throat. and therefore, having a lower llow resistance on the right side resulted in higher velocities on the right side. This, however, would not totally explain the variation. The B test series resulted in the same trend even though flow for this series was from the upper branch only. The geometry for the upper branch was symmetric about the vertical centerline of the hood. It appears that subtle factors can contribute to significant variations in the flow conditions. As a result, it is recommended that the design specify average control velocities sufficiently high to provide for unexpected variations in the velocities that may be caused by cross drafts, thermal drafts, motion of equipment, geometric conditions, or other unexpected conditions.

\subsection{Actual Flow Rate and Average Air Velocity Results}

Figures 12-19 show plots of the actual flow rates through the ducts and the total flow rates through the ventilation system as a function of time for each test run. These flow rates were determined from the duct velocity measurements recorded at 10-second intervals, during the dumping tests. Figures 20-27 document the average face and funnel throat air velocities for each test run as a function of time. The B lest series flow rates and, therefore, alo the velocities remained well controlled throughout the test.

The C rest series llow rates, which had llow only in the lower branch, varied signilicantly during the test. Early during the dumping, an upward spike appeared in the llow ratce and velocity results. This is particularly evident for the low flow conditions of the $\mathrm{C} 1$ test runs. It is anticipated that this is a result of a pressure surge as the dirt was rapidly displacing air during the dump causing a pressure wave. This was also visually evident from the dust plume that was created during the dump and the noticeable bellowing of the plastic seal between the box and funnel throat interface. 


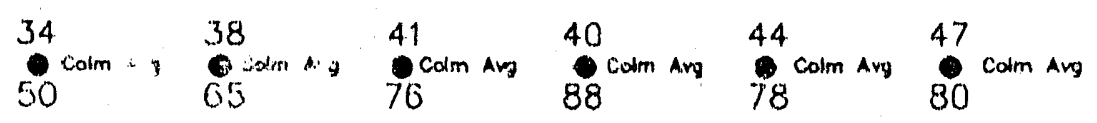

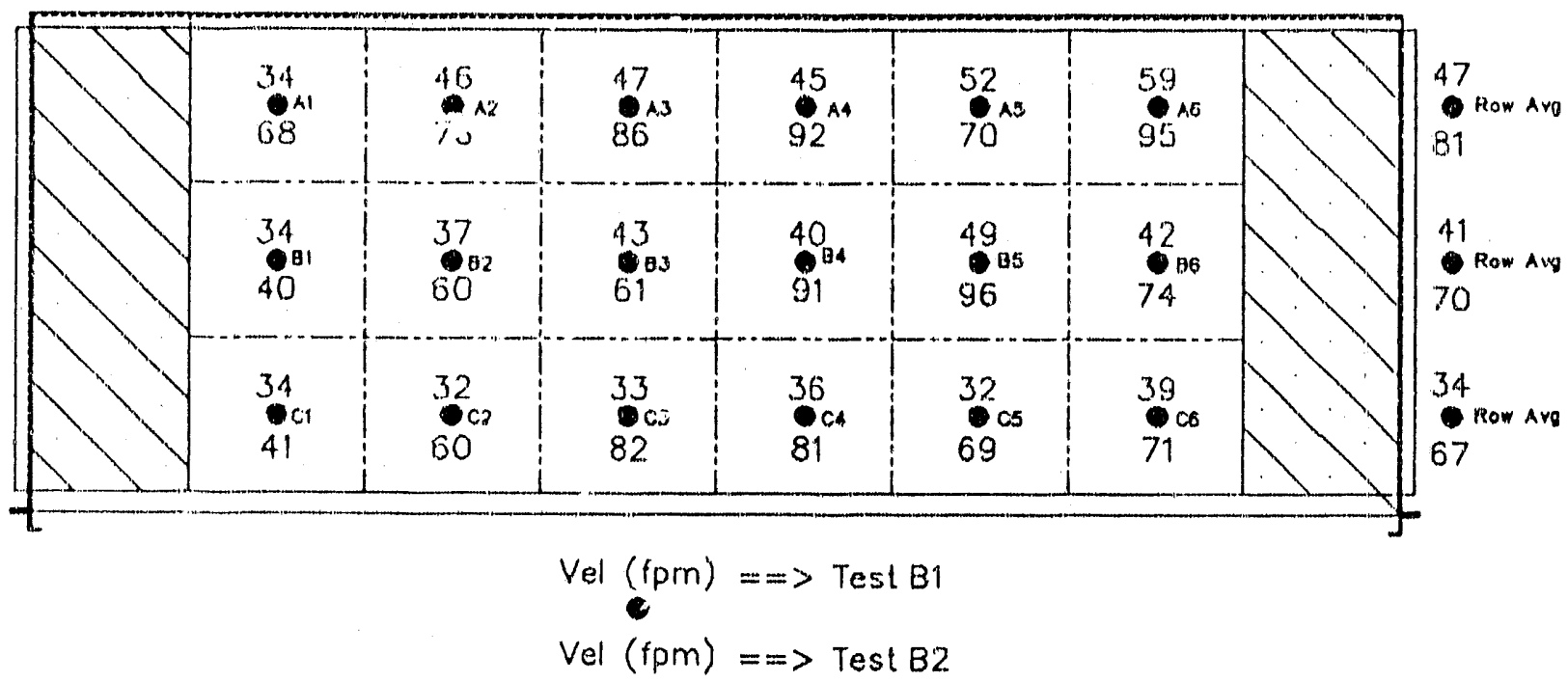

Figure 8. Test series B measured face velocities.

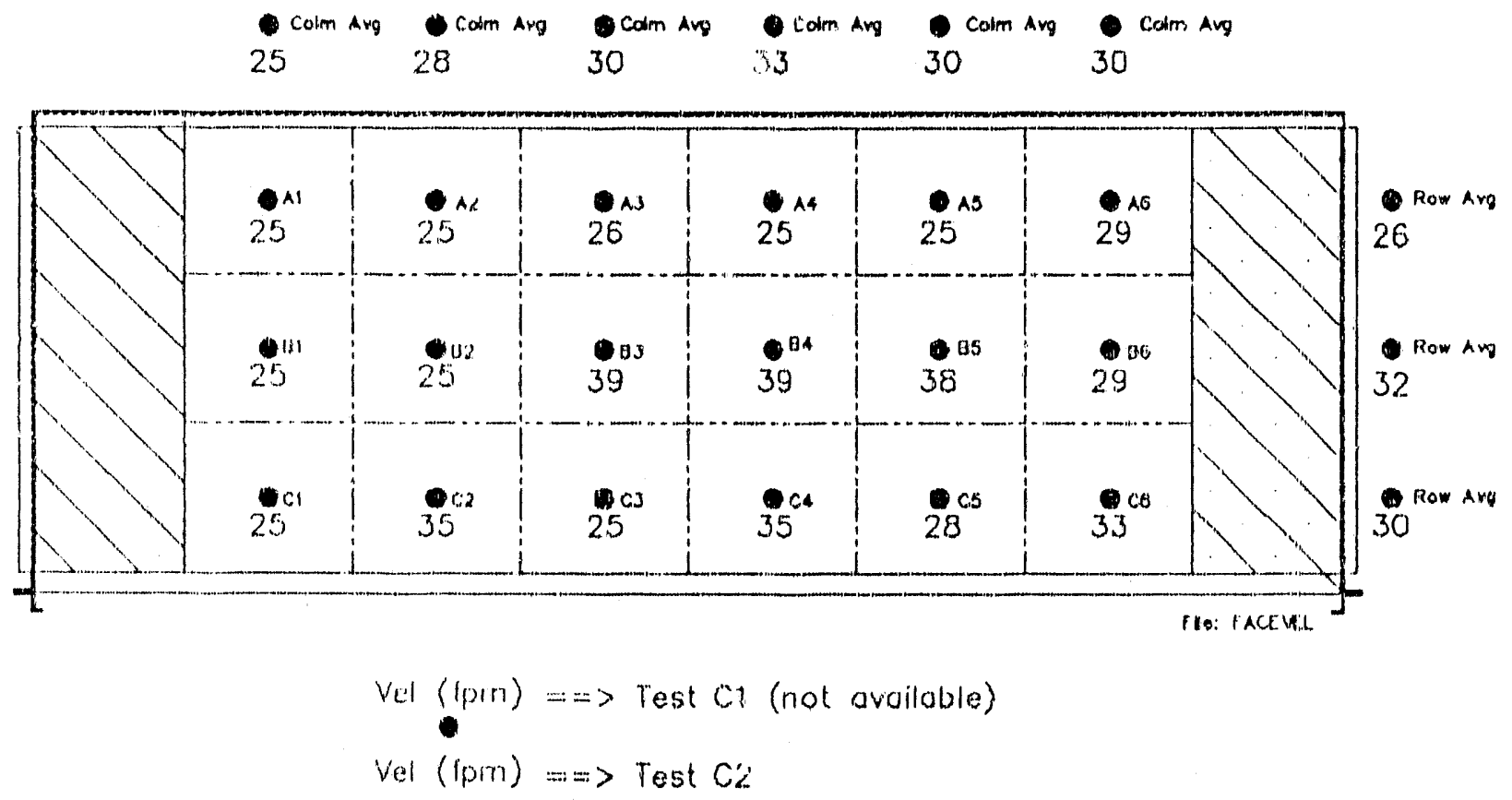

Figure 9. Test serics $C$ measured face velocities. 


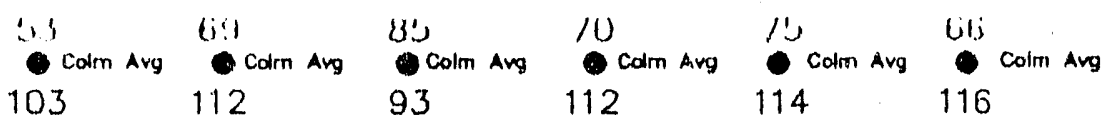

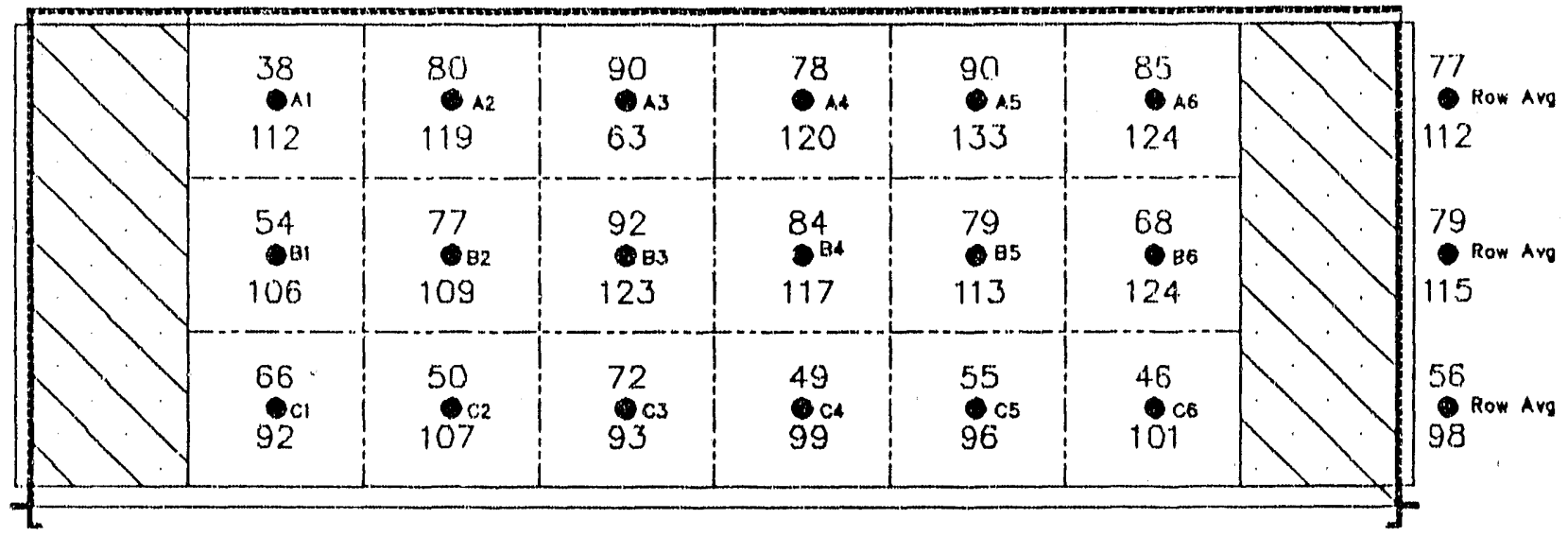

Vel $(\mathrm{fpm})==>$ Test 01

$\operatorname{Vel}(f p m)=:=>$ Test $D 2$

Figure 10. Test series D measured face velocities.
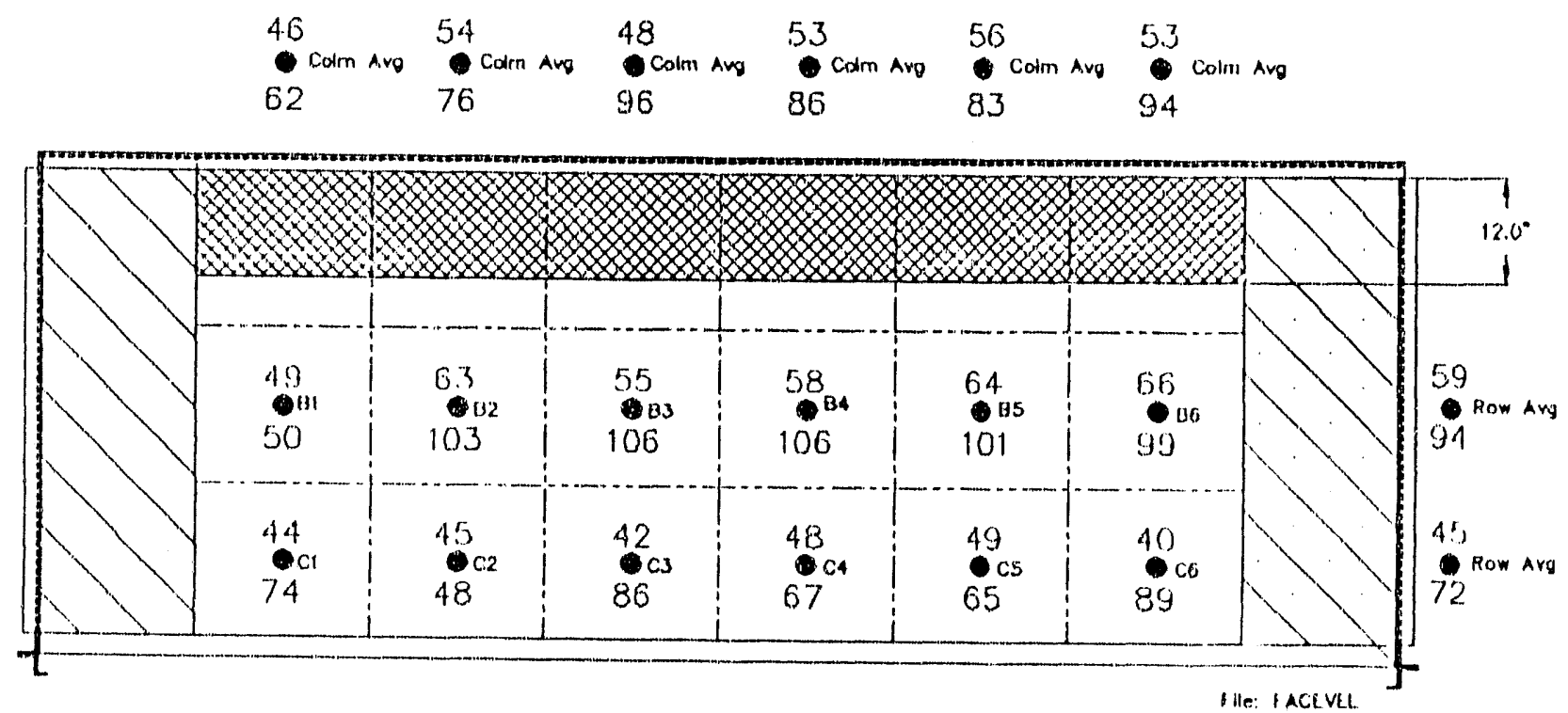

$\operatorname{Vel}(f p m)=\Rightarrow$ Test E1

$\operatorname{Vel}(f p m)==>$ Test E2

Figure 11. Test series $\mathrm{E}$ measured face velocities. 


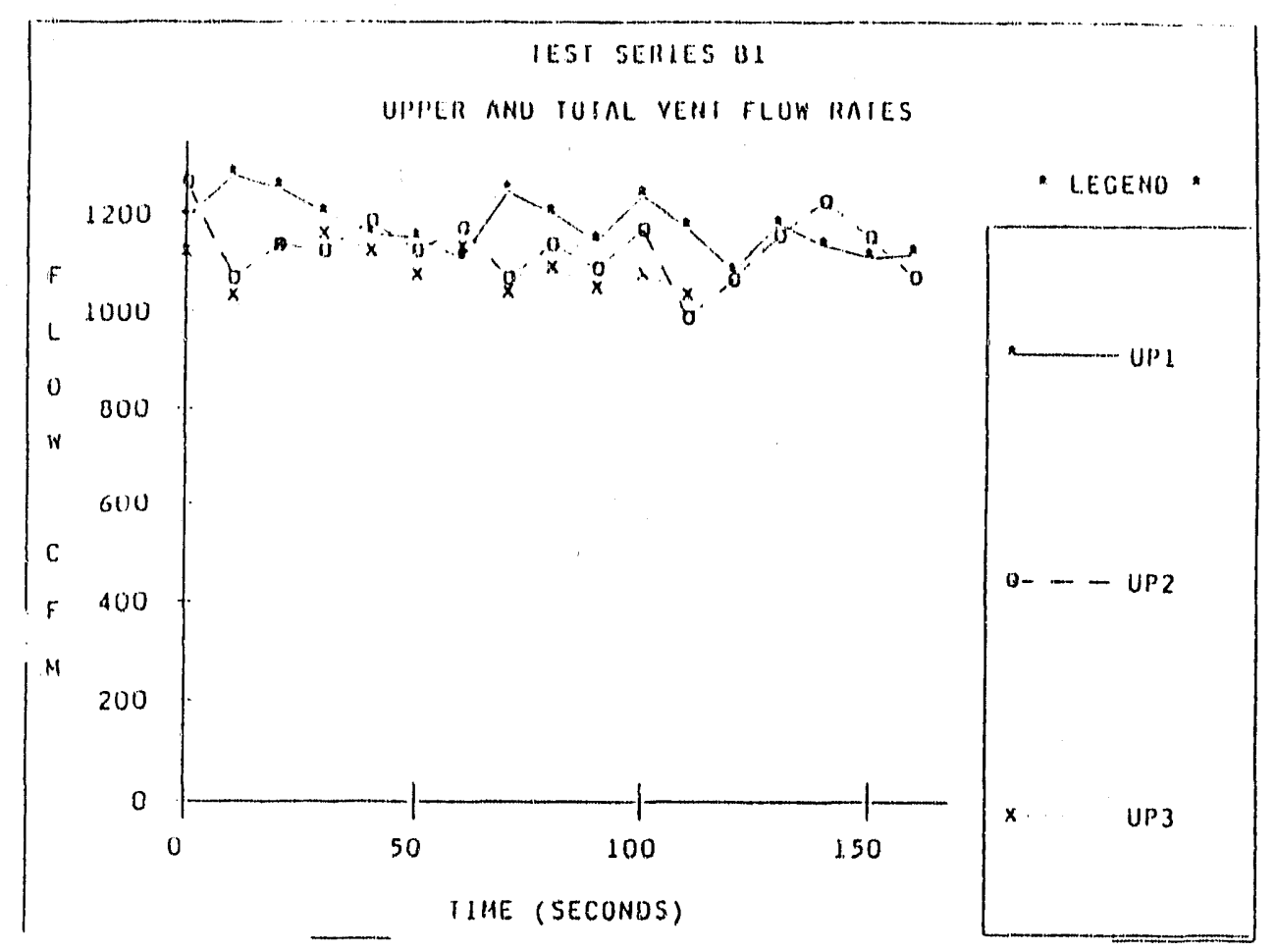

Figure 12. Test series B1 duct flows.

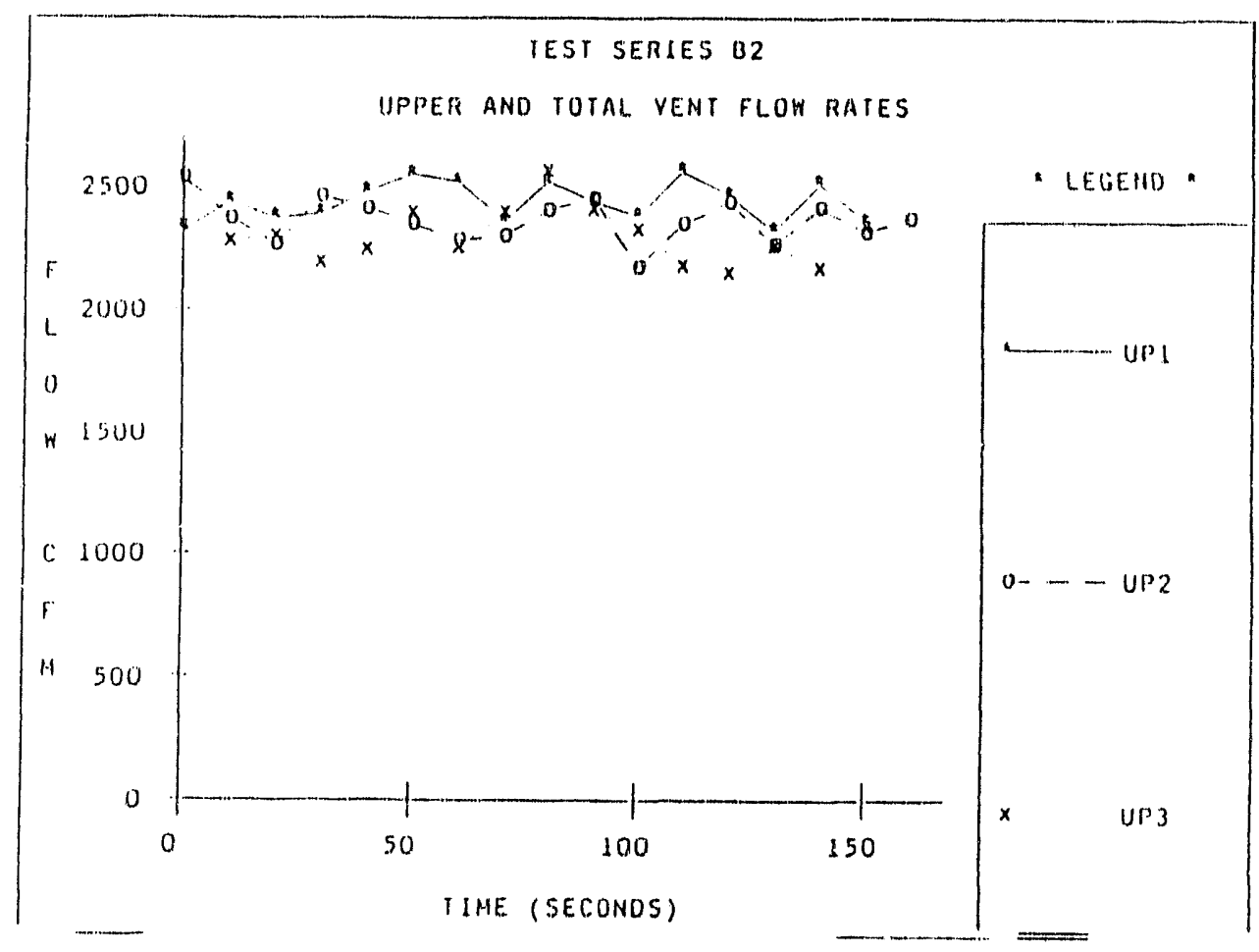

Figure 13. Test series B2 duct flows. 


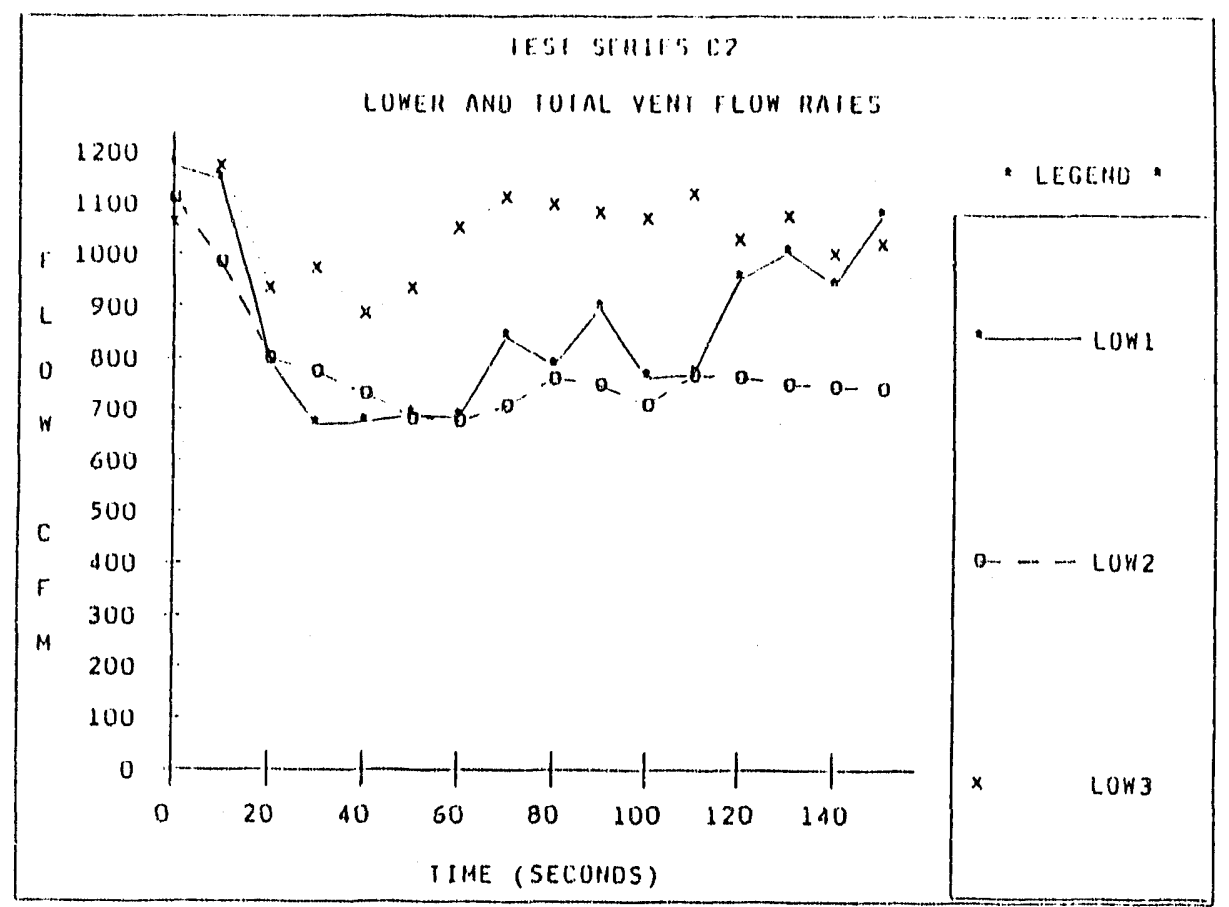

Figure 14. Test series $\mathrm{C} 1$ duct flows.

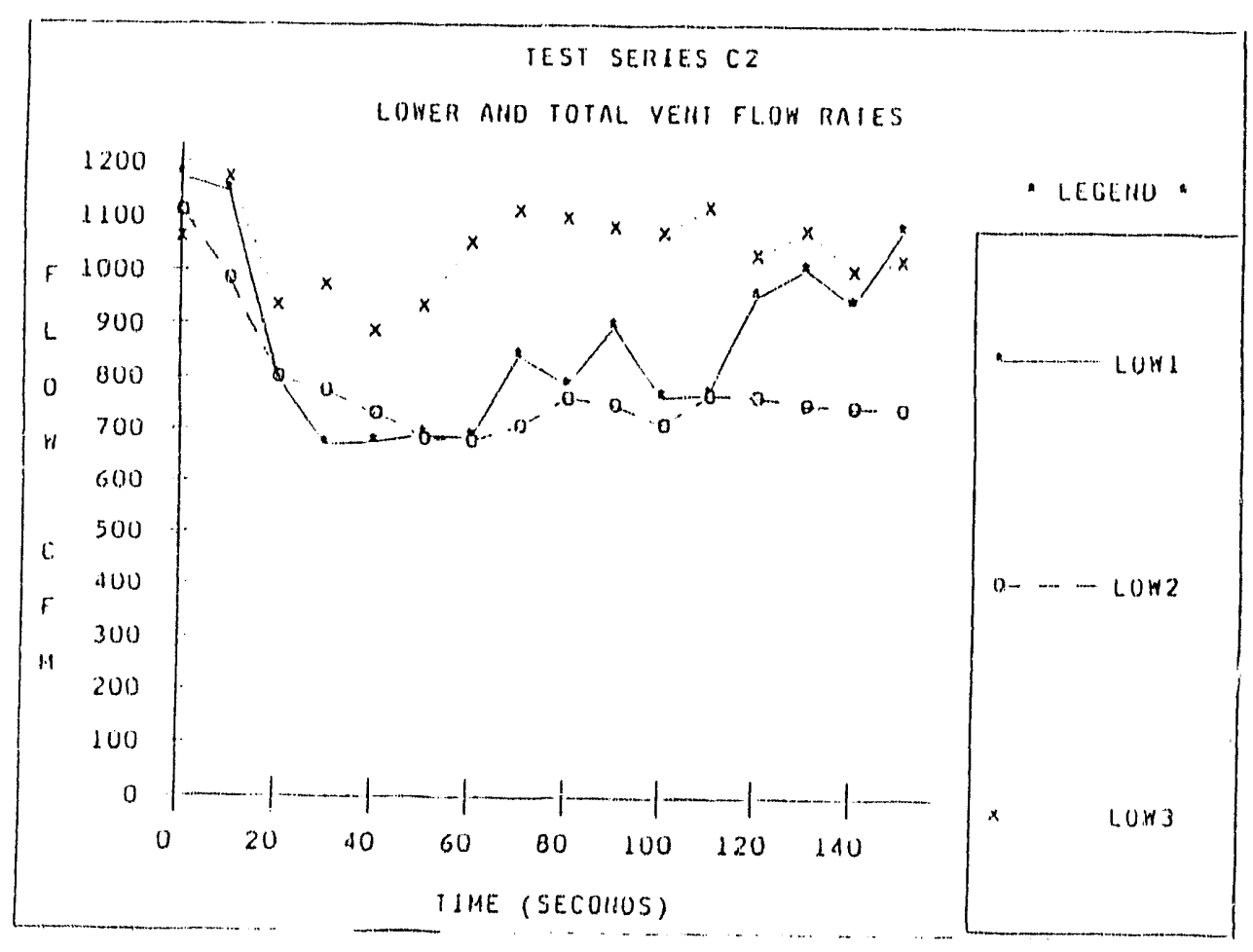

Figure 15. Test series C2 duct flows. 


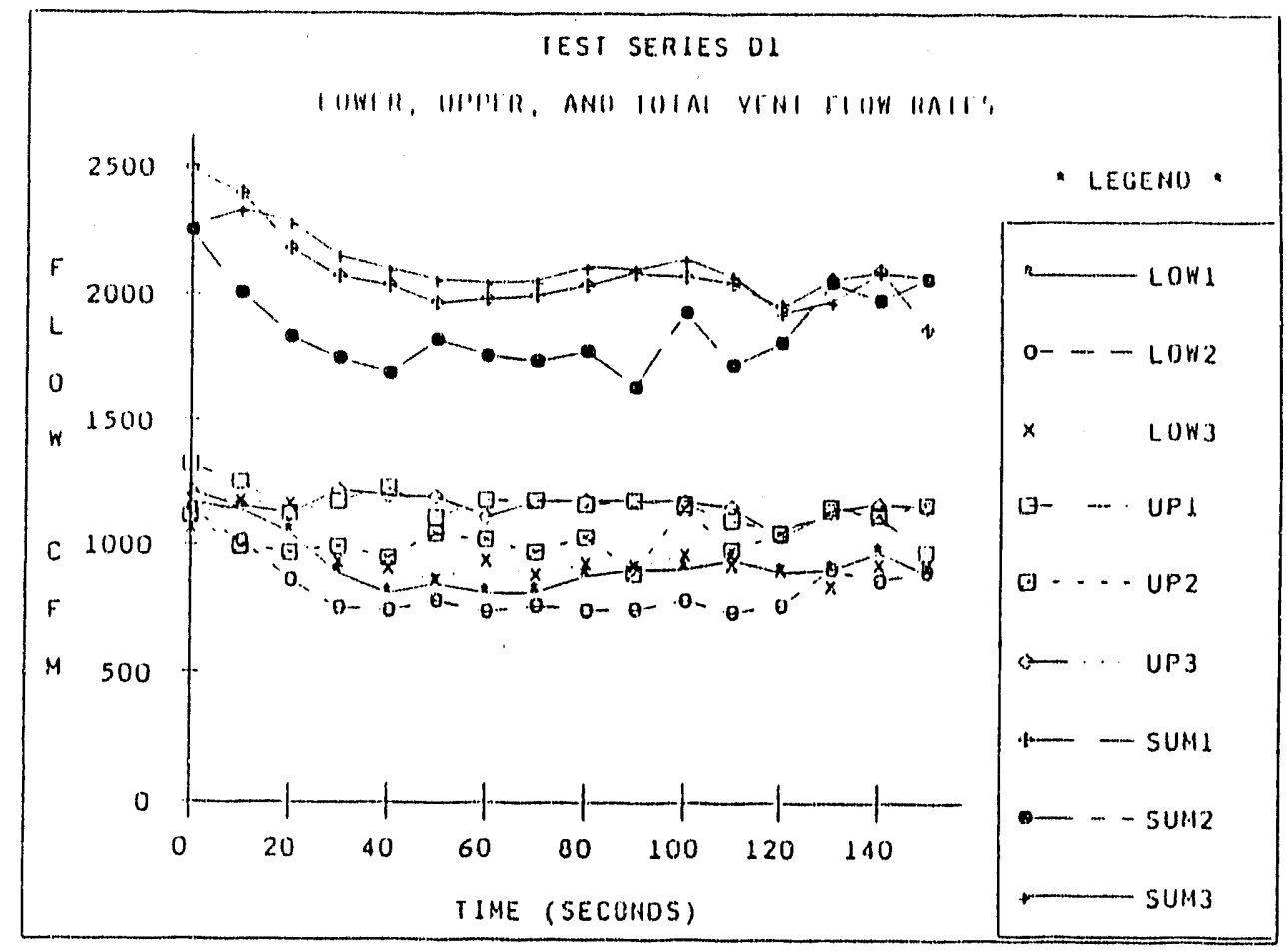

Figure 16. Test series D1 duct flows.

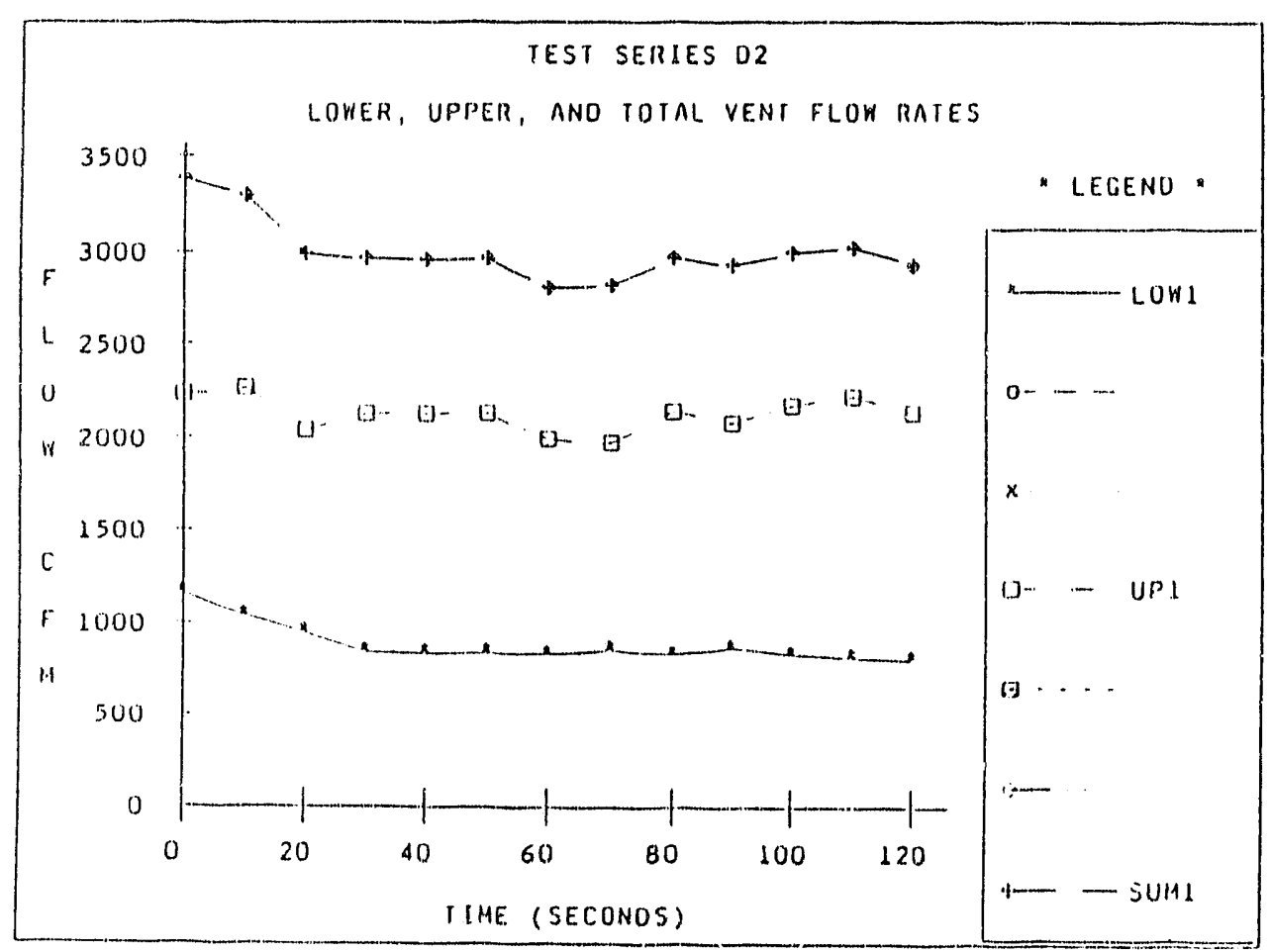

Figure 17. Test series D2 duct flows. 


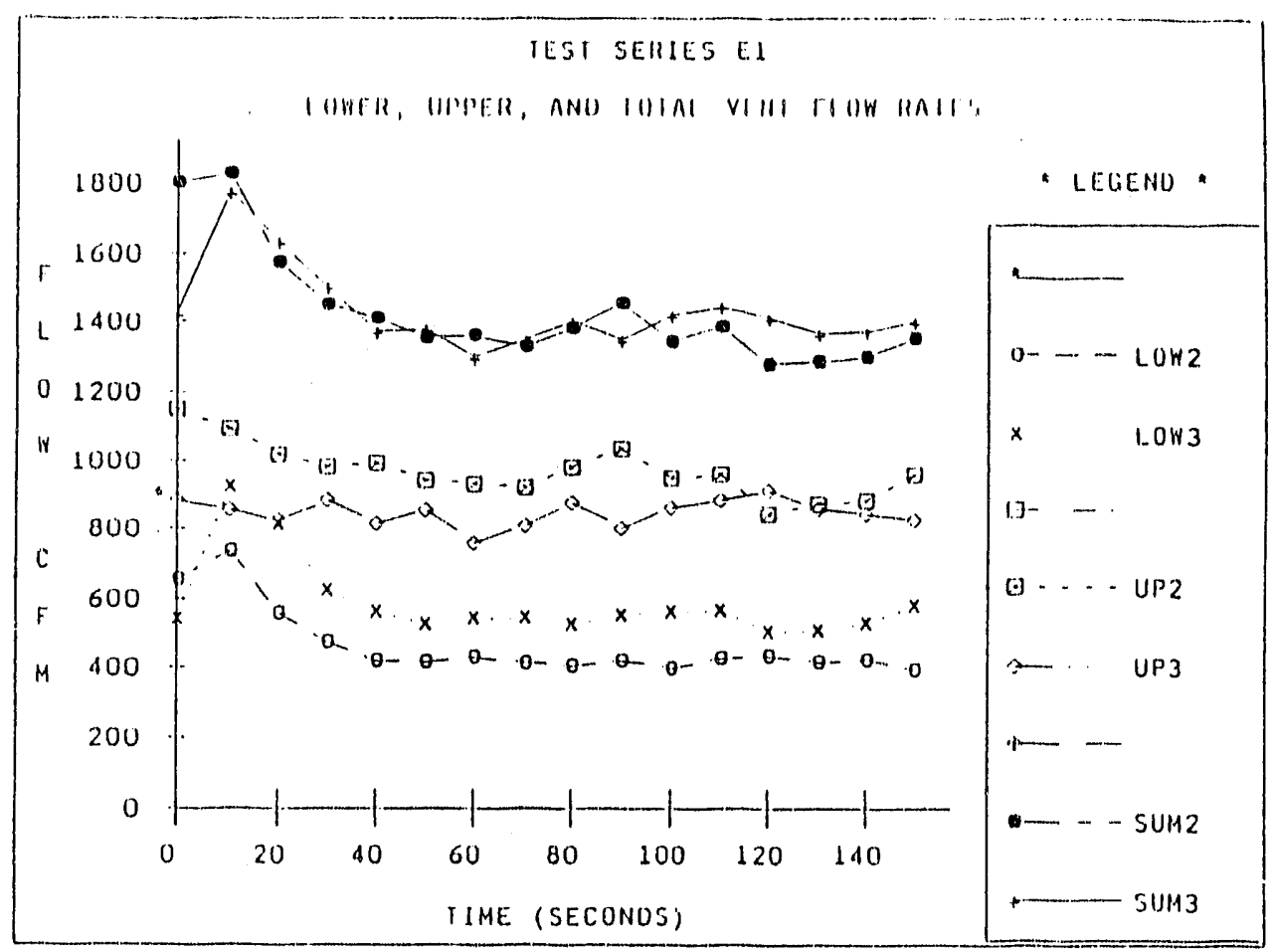

Figure 18. Test series E1 duct flows.

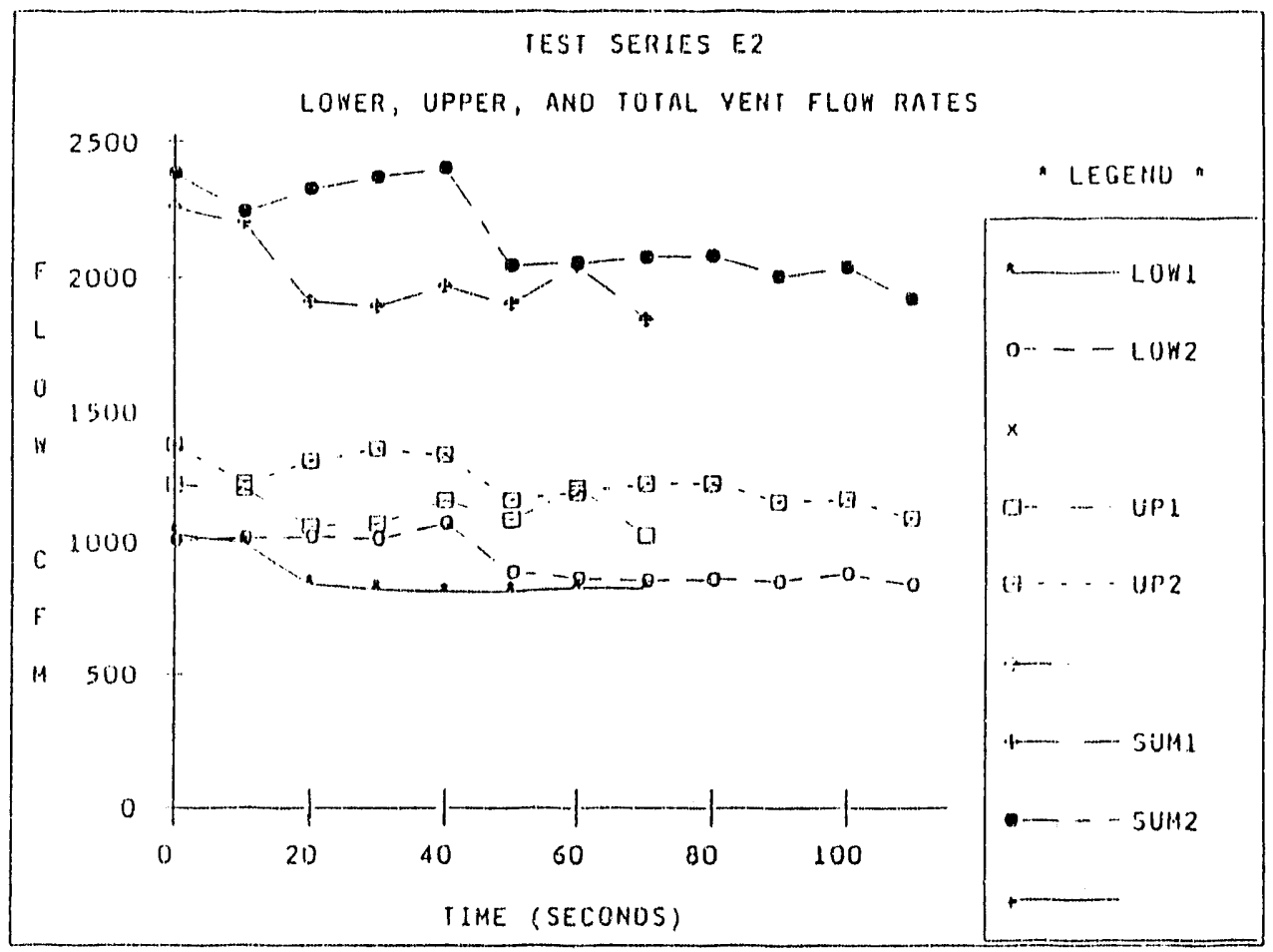

Figure 19. Test series E2 duct flows. 


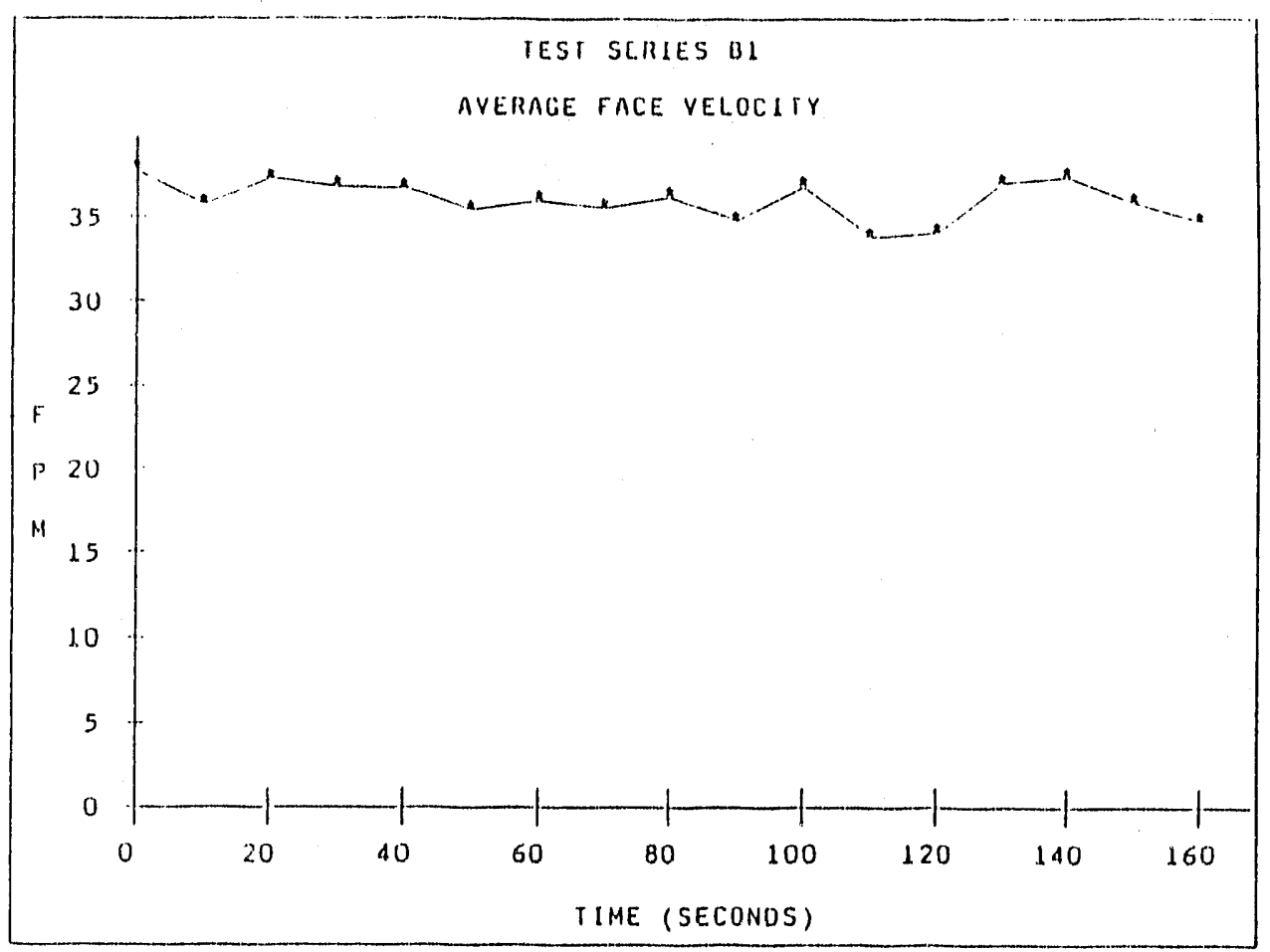

Figure 20. Test series B1 face velocities.

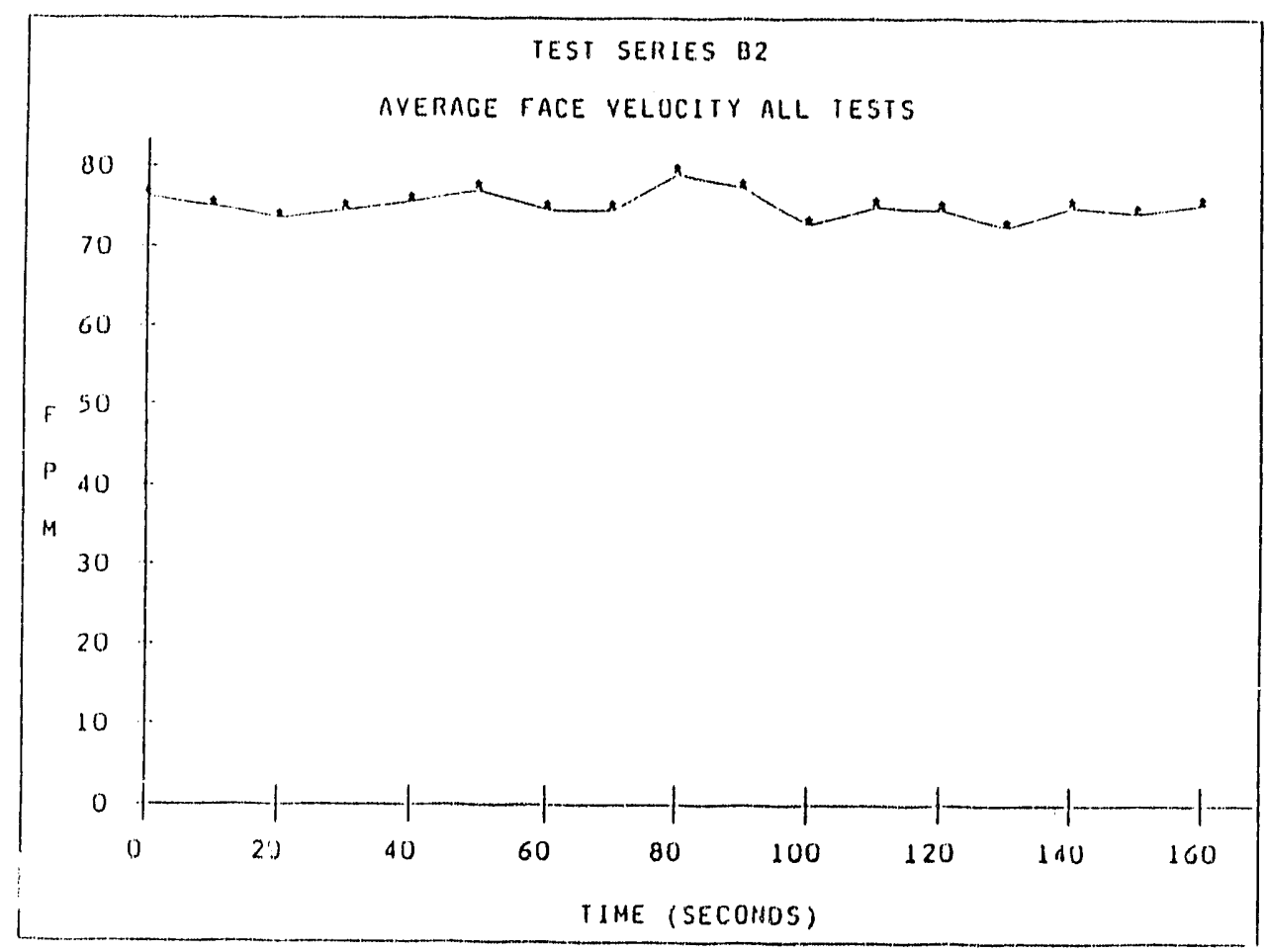

Figure 21. Test st ces B2 face velocities. 


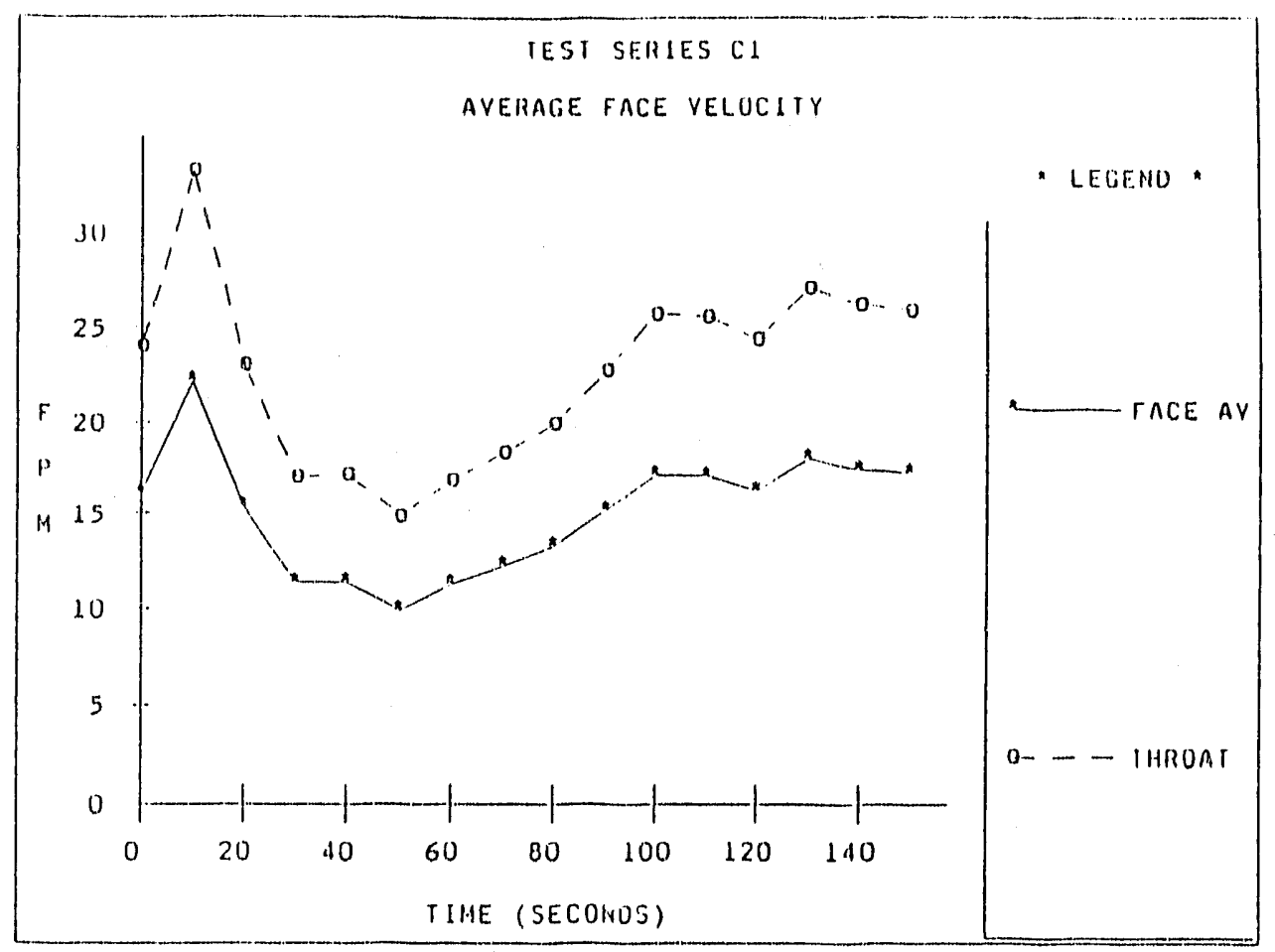

Figure 22. Test series $\mathrm{C} 1$ face velocitics.

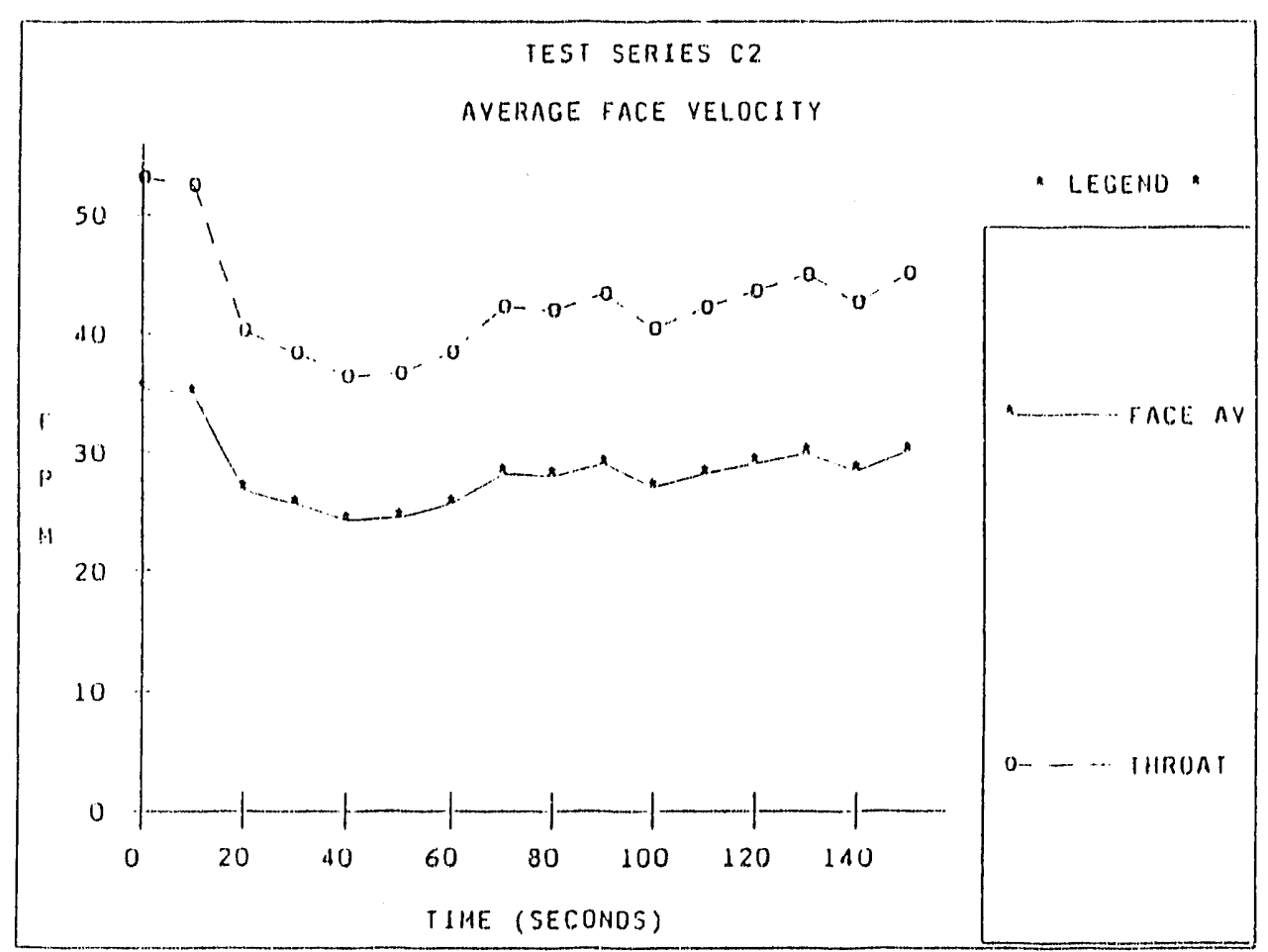

Figure 23. Test series $C 2$ face velocities. 


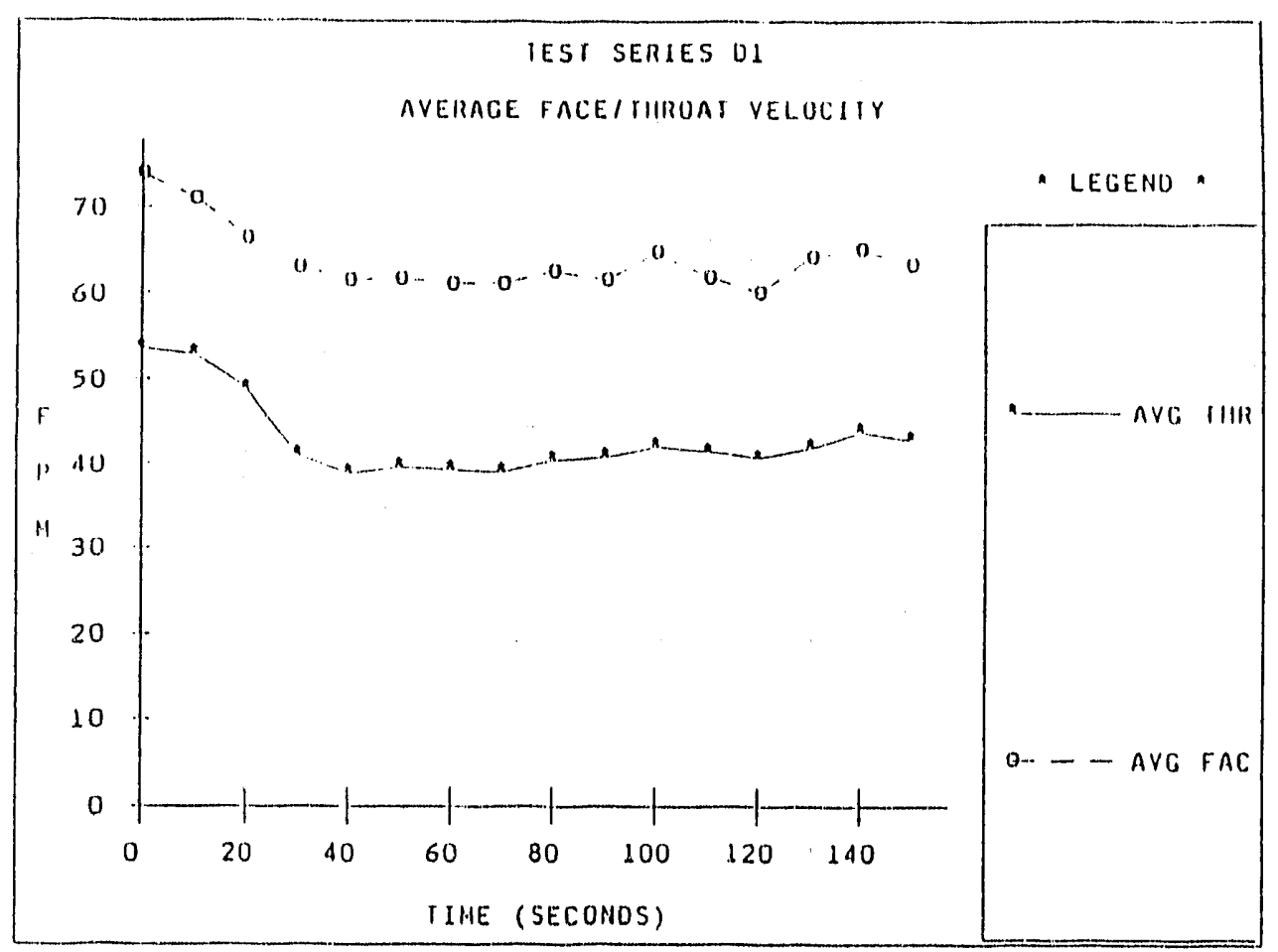

Figure 24. Test series D1 face velocities.

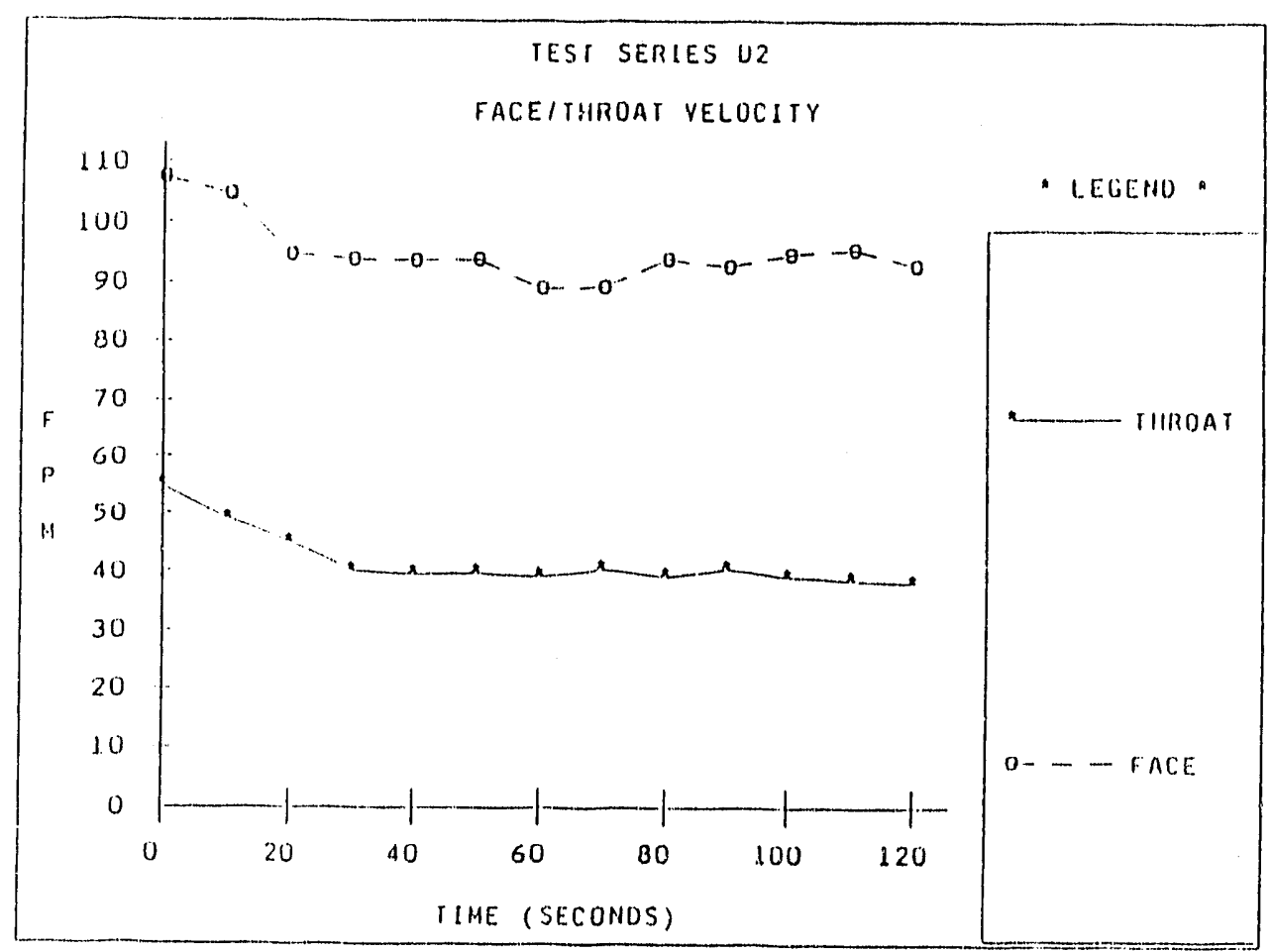

Figure 25. Test series D2 face velocities. 


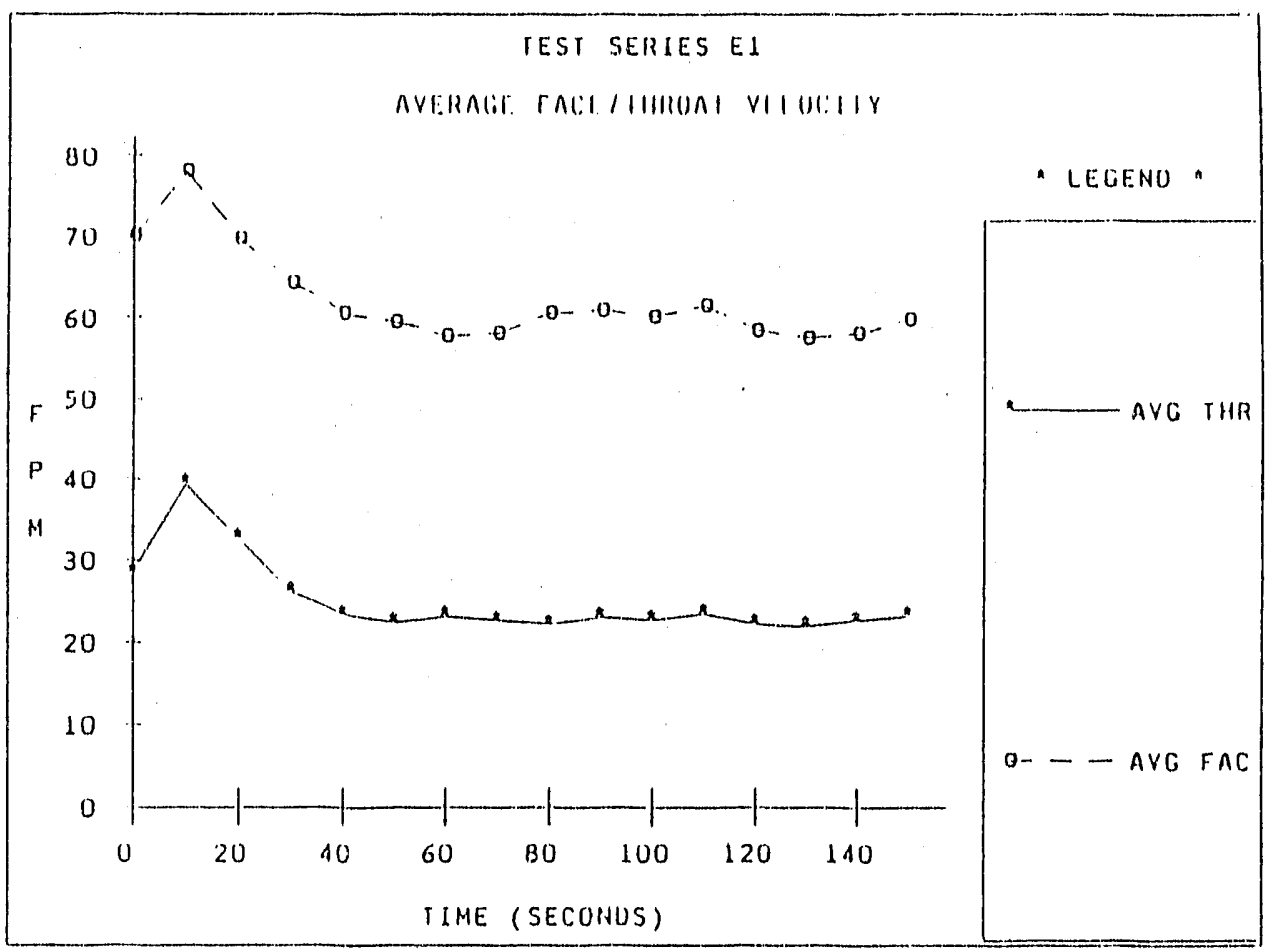

Figure 26. Test series E1 face velocities.

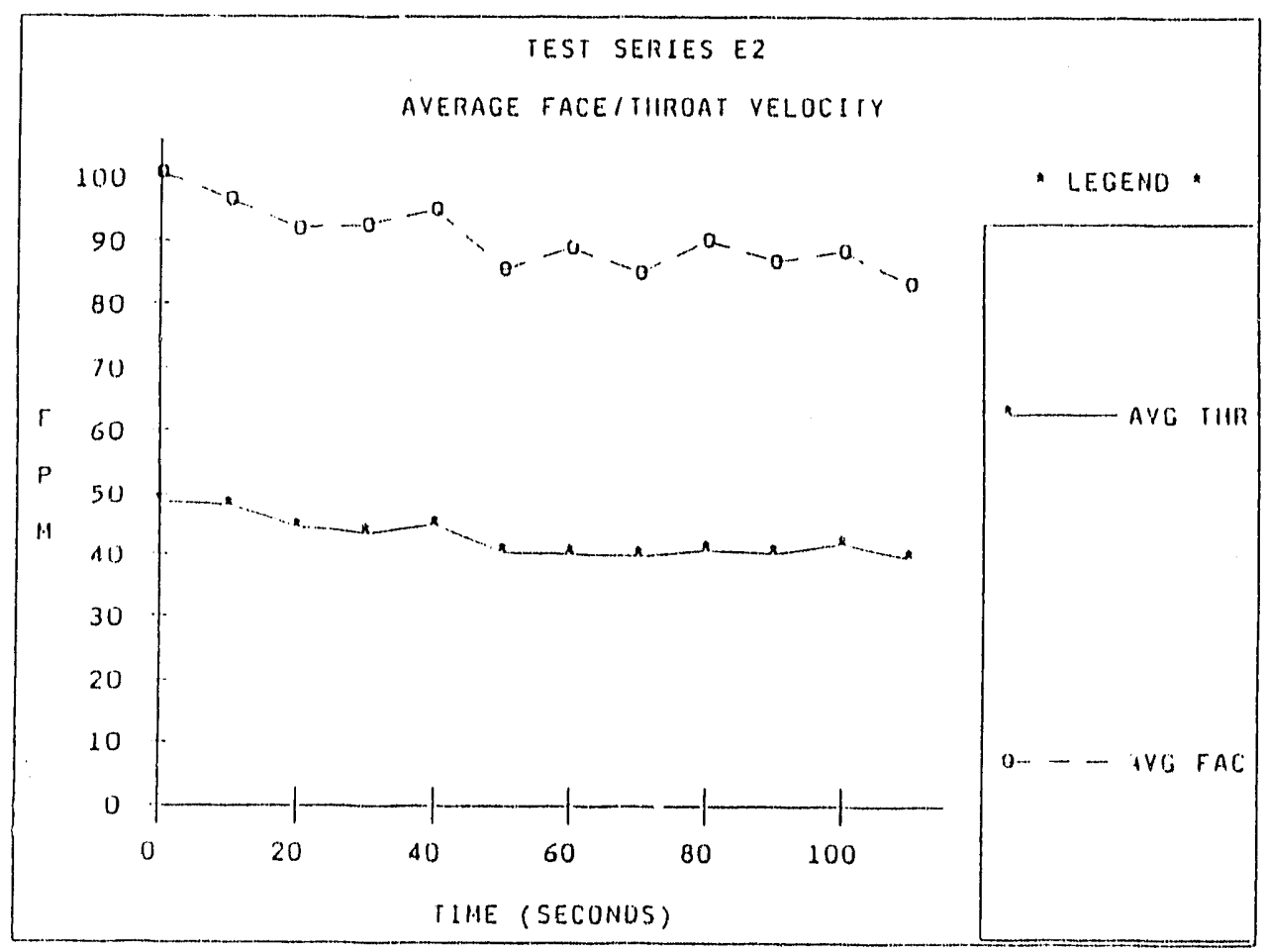

Figure 27. Test series E2 face velocities. 
The flow rate through the lower branch dropped, then in some cases recovered or partially recovered. This drop in flow rate was a result of the increased flow resistance due to the high concentration of dust in the lower portion of the funnel and drawn into the lower branch of ducting. Even after the dust cleared, the dust loading on the filters was sufficient to increase the system resistance sufficiently that the system flow rate did not fully recover in some cases. Sirce the filters were not cleaned after every test run, the amount of recovery varied even for the same test series (e.g., test C2). The system needs to be designed to accommodate the increased flow resistance as a result of high dust concentrations in the air and filter loading. One method to accomplish this is to select and operate the fan with a steep reassure curve such that a change in the system resistance will not result in large flow volume changes.

Table 2 shows a comparison of the desired duct velocities compared to the average measured velocities for each test. Differences in the actual measured velocities from the desired velocitis can be attributed to the loading of the HEPA filter during testing and changes in air density due to dust loading. In most cases the average measured duct velocity was within $+1-10 \%$ of the desired velocity.

\subsection{Air Sampling Results}

A relative measure of the dust that escaped the hood for each test sequence was obtained by calculating a three-minute-time-weighted average of the dust concentration as measured by each air

Table 2. Measured duct velocity compared to desired duct velocity.

\begin{tabular}{|c|c|c|c|c|}
\hline Test ID. & $\begin{array}{c}\text { Desired } \\
\text { upper duct flow } \\
\text { (lfpm) }\end{array}$ & $\begin{array}{l}\text { Desired } \\
\text { lower duct } \\
\text { flow } \\
\text { (lfpm) }\end{array}$ & $\begin{array}{c}\text { Avg } \\
\text { upper } \\
\text { duct flow } \\
\text { (lfpm) }\end{array}$ & $\begin{array}{l}\text { Avg } \\
\text { lower } \\
\text { duct flow } \\
\text { (lfpm) }\end{array}$ \\
\hline A1 & () & 0 & - & - \\
\hline B1 & 1000 & 0 & $972.5+/-32.3$ & 0) \\
\hline B2 & $20(0)$ & 0 & $2025.7+/-44.9$ & 0 \\
\hline $\mathrm{Cl}$ & 0 & 1000 & 0 & $951.8+/-207$ \\
\hline $\mathrm{C} 2$ & 0 & 2100 & 0 & $1789+/-200$ \\
\hline D1 & 1000 & 2100 & $1005.9+/-33.4$ & $18(44+/-195$ \\
\hline D2 & 2000 & 2100 & $1818.3+!-77.1$ & $1750+/-32$ \\
\hline $\mathrm{E} 1^{a}$ & 770 & 1000 & $777.1+/-37.7$ & $1049+/-201$ \\
\hline $\mathrm{E} 2^{\mathrm{a}}$ & 1000 & 2000 & $1014.9+/-51.4$ & $1790+/-133$ \\
\hline
\end{tabular}


sampler. This was obtained by taking the dust mass (grams) collected on the lilter and dividing the mass by the volunic (liters) of air pulled through the filter during the 3-minutes following the initiation of the dump. The resulting average air concentrations along with the standard deviations for the three test runs of each test sequence are presented in Tables 3-6. Although samples were collected at 8 separate locations around the test assembly ( 4 samplers located around the hood face opening and 4 samplers located around the funnel and box junction), sample results were only reported for those samples collected around the hood face opening. The results from samples located around the funnel box junction showed that the amount of dust collected was wholly dependent on the quality of the tape seal around the box. It was noted that during testing the quality of this seal was not consistent from test to test. This introduced a high deviation from test to test in the amount of dust collected at a particular sample point. For this reason the test data from the four samplers around the funnel and box junction were discarded in the calculation of the dust removal efficiency of the different test configurations.

The air concentration results from the samplers were then used to provide a quantitative measure of the efficiency of controlling the dust (i.e., preventing the dust from escaping the hood). The air concentration results were also used to calculate a dust control efliciency $\left(\mathrm{C}_{\mathrm{erf}}\right)$ and a control factor (CF) relative to the no-flow baseline case using the calculation methods found in Appendix A of this report.

Figures 28-29 show the control efficiencies and control factors for all tests and the standard deviations of those calculations to the 2 sigma confidence level. 
Table 3. Test scries B data summary.

\begin{tabular}{|c|c|c|c|c|c|c|c|c|c|c|c|c|}
\hline & & D & UST COWC & NTRATION & 5167 & & & & & & & \\
\hline SAMPLER & & A1 & & & $B 1$ & & & B2 & & & & \\
\hline MU:IIINA & & AVi: & & & $A \cup r_{1}$ & & & Avi & & & & \\
\hline 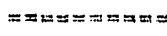 & 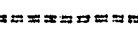 & $=\pi x=30$ & 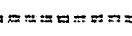 & 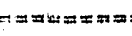 & $x=m=x$ & $\Rightarrow=m=m=m$ & $==z=10=2=$ & 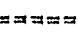 & 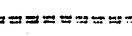 & & & \\
\hline 1 & $2,2 \theta-03$ & $+1-$ & $9.2 \theta-04$ & $2.4 \theta-05$ & $+1-$ & $1.3 e=05$ & $0.10-05$ & $+1-$ & $1.6 \theta-05$ & & & \\
\hline 2 & $2.5 \theta-03$ & $+1-$ & $1.60-03$ & $1.20-03$ & $+1-$ & $2.10-03$ & $2.10-05$ & $+1-$ & $2.3 e-05$ & & & \\
\hline 3 & $6.90-03$ & $+1-$ & $3.5 \theta-03$ & $8.9 e-04$ & $+1-$ & $1.2 \theta-0.3$ & 1. $5 \theta-04$ & $+1-$ & $7.8 \theta-05$ & & & \\
\hline 4 & $6.70-03$ & $+1-$ & $2.60-03$ & $9.6 a-04$ & $+1-$ & $8.30-04$ & $6.30-0.05$ & $+1-$ & $2.20-05$ & & & \\
\hline & & & & & $B$ & SERIES & ESTS & & & & & \\
\hline & & & 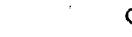 & NTROL FA & CTORS & AND CO & ROL EFFI & CIENC & EIES & & & \\
\hline SAMPLER & & B1 & & & B1 & & & 82 & & & B2 & \\
\hline POSITION & & $C F$ & & & CEFF & & & $\mathrm{CF}$ & & & CEFF & \\
\hline 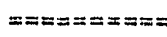 & $\alpha=m=m=\pi=$ & $= \pm=x=$ & 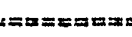 & ي" & $m=2 \pi x$ & 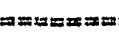 & 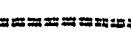 & $F== \pm$ & 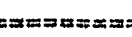 & $\Rightarrow= \pm=x=$ & $=m===x$ & $== \pm==-$ \\
\hline 1 & 91.6 & $+1-$ & 61.4 & 98.9 & $+/-$ & 0.7 & 24.2 & $+1-$ & 11.0 & 95.9 & $+1-$ & 1.9 \\
\hline 2 & 2.0 & $+1-$ & 3.7 & 50.8 & $+/-$ & 99.2 & 119.9 & $+1-$ & 151.2 & 99.2 & $+/-$ & 1.1 \\
\hline 3 & 7.8 & $+/-$ & 11.2 & 87.1 & $+1-$ & 18.6 & 46.2 & $+1-$ & 33.5 & 97.8 & $+1-$ & 1.6 \\
\hline 4 & 7.0 & $+1-$ & 6.7 & 85.7 & $+/-$ & 13.6 & 106.3 & $+1-$ & 56.1 & 99.1 & $+/-$ & 0.5 \\
\hline AVG. & 27.1 & $+1-$ & 20.7 & 80.6 & $+/-$ & 30.6 & 74.1 & $+/-$ & 63.0 & 98.0 & $+1-$ & 1.2 \\
\hline
\end{tabular}

Table 4. Test scries C data summary.

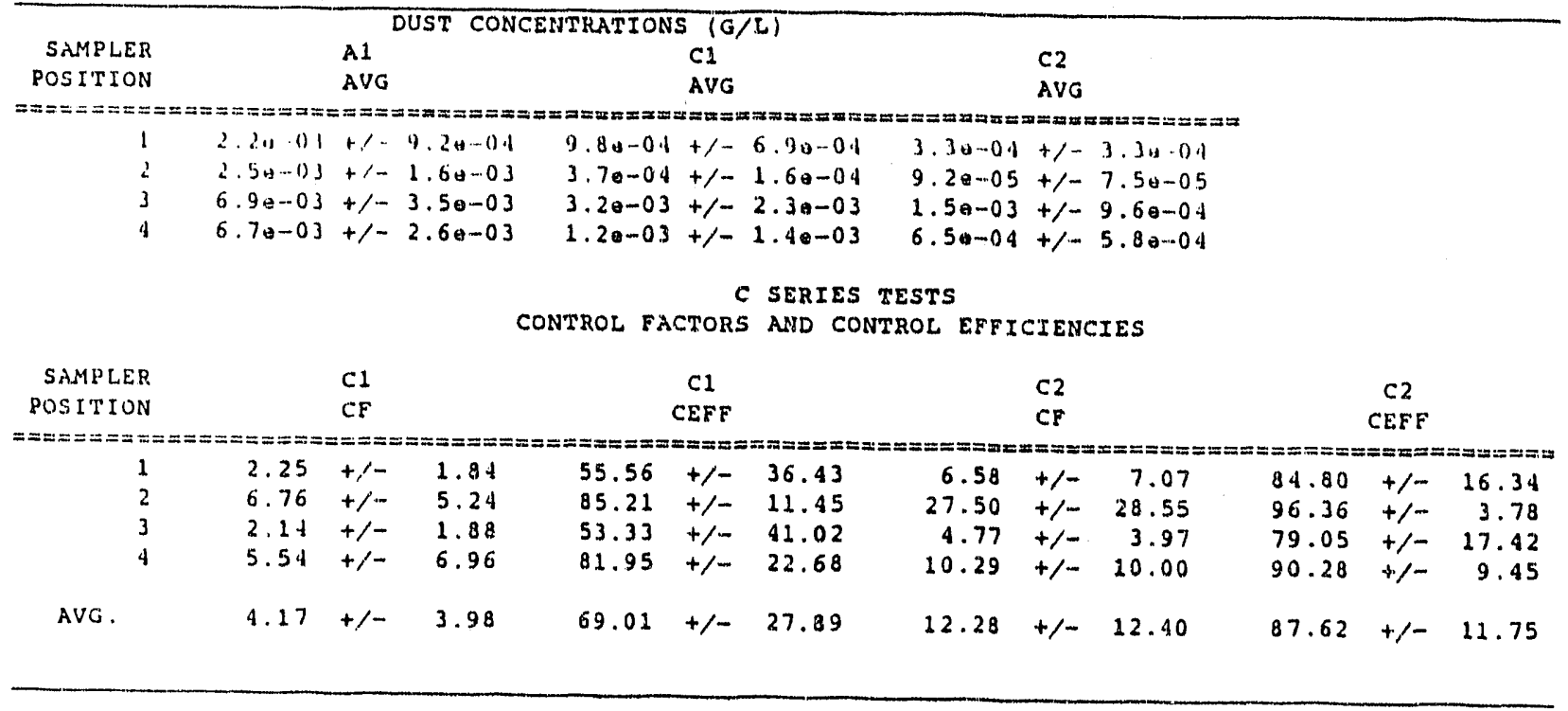


Table 5. 'l'est scries D dala summary.

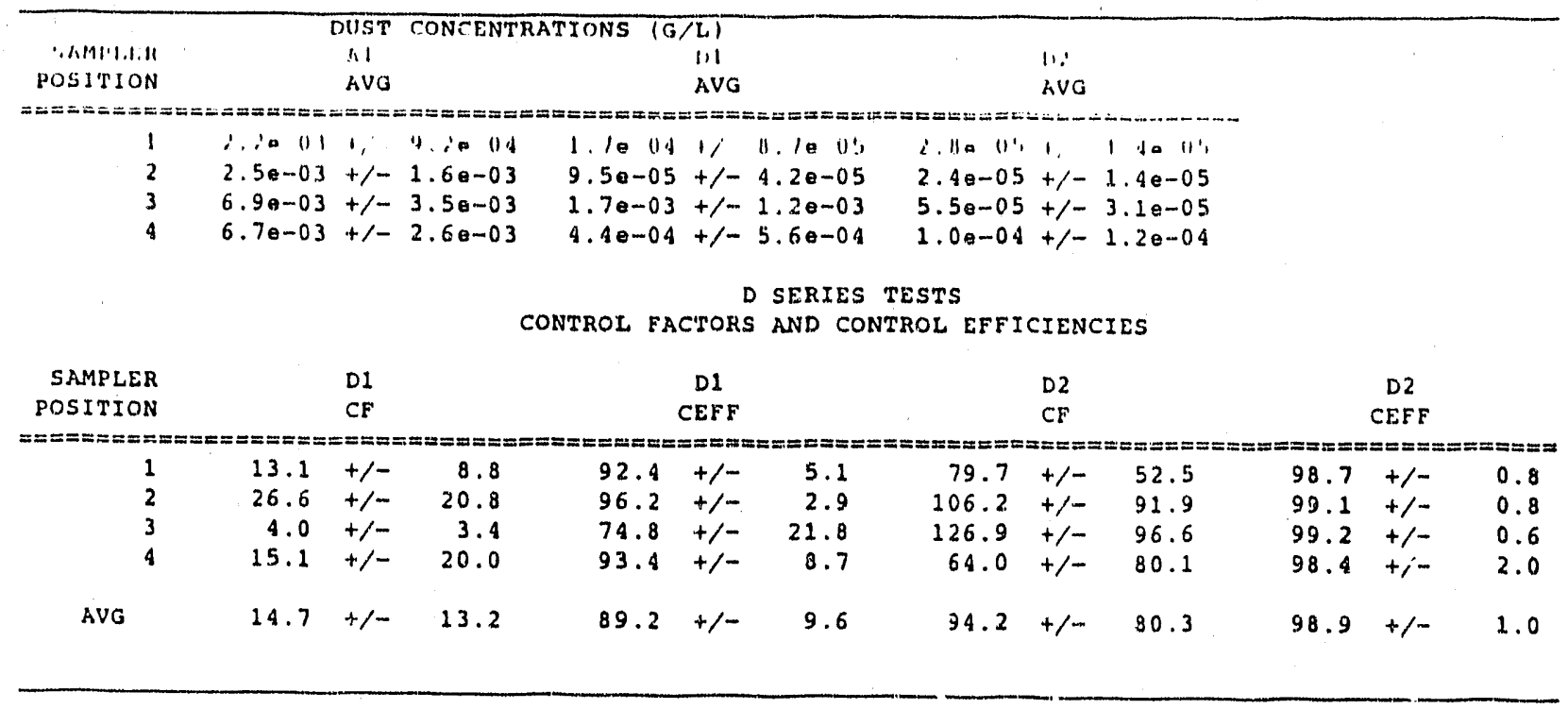

Table 6. Test series E data summary.

\begin{tabular}{|c|c|c|c|c|c|c|c|c|c|c|c|c|}
\hline \multicolumn{13}{|c|}{ DUST CONCENTRATIONS $(\mathrm{G} / \mathrm{L})$} \\
\hline SRMPLER & \multicolumn{3}{|c|}{ A1 } & \multicolumn{3}{|c|}{ E1 } & \multicolumn{3}{|c|}{$\varepsilon 2$} & & & \\
\hline POSITION & \multicolumn{3}{|c|}{ AVG } & \multicolumn{3}{|c|}{ AVG } & \multicolumn{3}{|c|}{ AVG } & & & \\
\hline \multicolumn{13}{|c|}{ 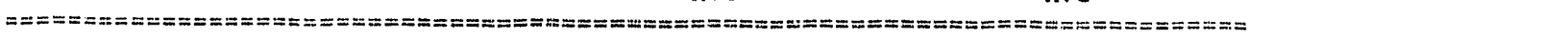 } \\
\hline 1 & $2.2 e-03$ & $+1-$ & $9.2 e-04$ & $1.80-04$ & $+1-1$ & $1.6 e-04$ & $2.6 \theta-05$ & $+/-$ & $2.9 e-05$ & & & \\
\hline 2 & $2.5 e-03$ & $+/ \cdots$ & $1.6 \mathrm{e}-03$ & $1.3 \theta-04$ & $+/-1$ & $1.10-04$ & $1.6 e-05$ & $+1-$ & $1.4 e-05$ & & & \\
\hline 3 & $6.90-03$ & $+1-$ & $3.5 e-03$ & $8.00-04$ & $+1-$ & $7.3 \theta-04$ & $1.60-04$ & $+1-$ & $1.2 \epsilon-04$ & & & \\
\hline 4 & $6.7 e-03$ & $+/-$ & $2.6 e-03$ & $1.50-04$ & $+/-1$ & $1.20-04$ & $5.6 \cdot-05$ & $+1-$ & $4.3 \theta-05$ & & & \\
\hline & \multicolumn{12}{|c|}{ E SERIES TESTS } \\
\hline & \multicolumn{12}{|c|}{ CONTROL FACTORS AND CONTROZ EFFICIENCIES } \\
\hline SIMPLER & \multicolumn{3}{|c|}{ E1 } & \multicolumn{3}{|c|}{ E 1} & \multicolumn{3}{|c|}{ E2 } & \multicolumn{3}{|c|}{ E2 } \\
\hline POSITION & \multicolumn{3}{|c|}{$\mathrm{CF}$} & \multicolumn{3}{|c|}{ CEFF } & \multicolumn{3}{|c|}{$\mathrm{CF}$} & \multicolumn{3}{|c|}{ CEFF } \\
\hline \multicolumn{13}{|c|}{ 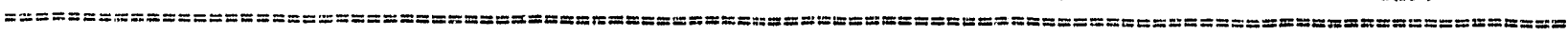 } \\
\hline 1 & 12.1 & $+1-$ & 11.6 & 91.8 & $+1-$ & 7.9 & 84.0 & $+1-$ & 98.8 & 98.8 & $+1-$ & 1.4 \\
\hline 2 & 19.5 & $+1-$ & 20.9 & 94.9 & $+1-$ & 5.5 & 159.4 & $+1-$ & 172.1 & 99.4 & $+1-$ & 0.7 \\
\hline 3 & 8.6 & $+1-$ & 9.0 & 88.4 & $+/-$ & 12.1 & 44.6 & $+1-$ & 40.3 & 97.0 & $+1-$ & 2.0 \\
\hline 4 & 45.0 & $+1-$ & 39.3 & 97.8 & $+1-$ & 1.9 & 118.6 & $+/=$ & 100.7 & 99.2 & $+1-$ & 0.7 \\
\hline$\therefore$ AVG & 21.3 & $+1-$ & 20.2 & 93.2 & $+1-$ & 6.9 & 101.6 & $+1-$ & 103.0 & 98.8 & $+1-$ & 1.2 \\
\hline
\end{tabular}




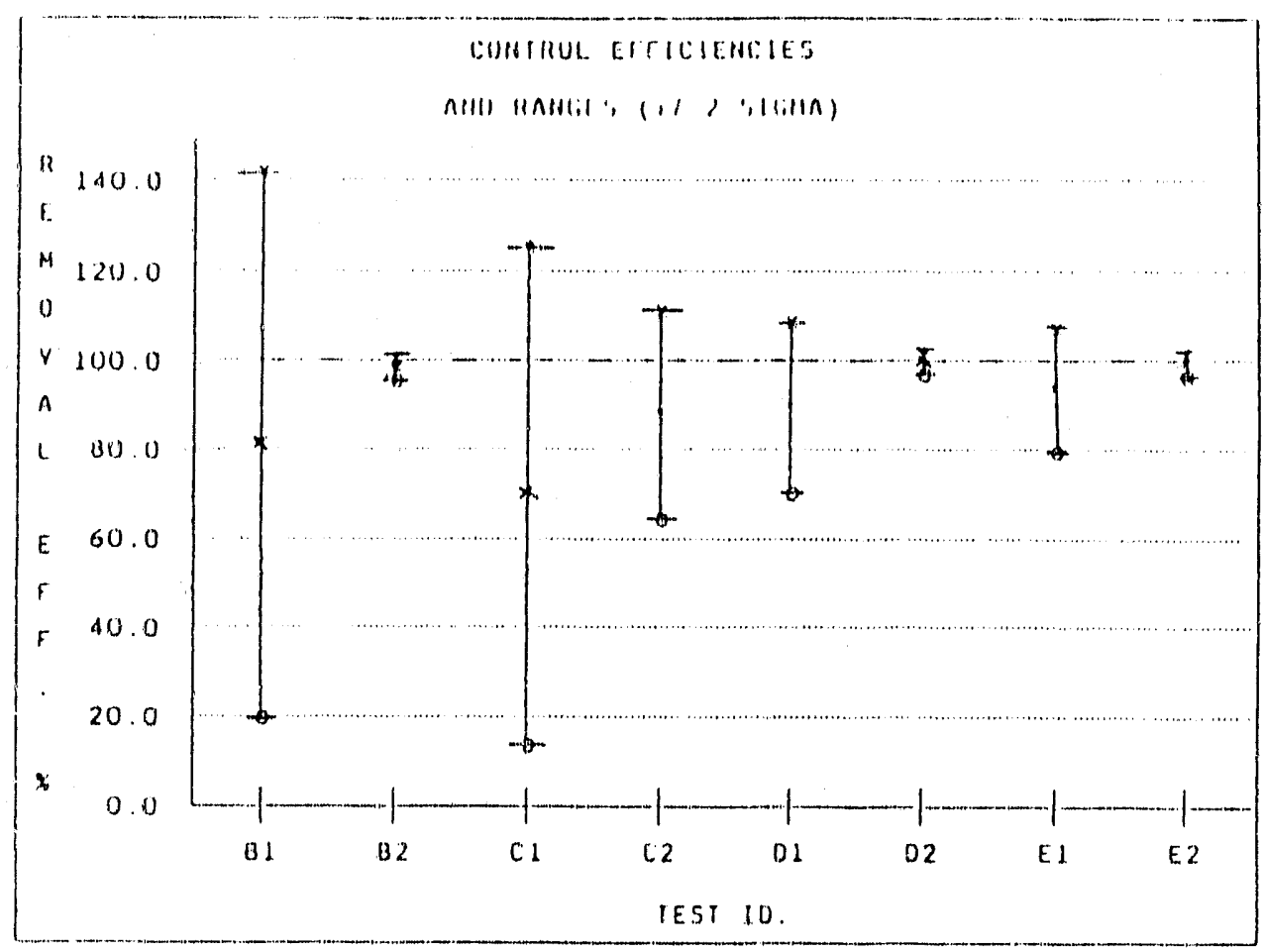

Figure 28. Control efficiencies of all tests.

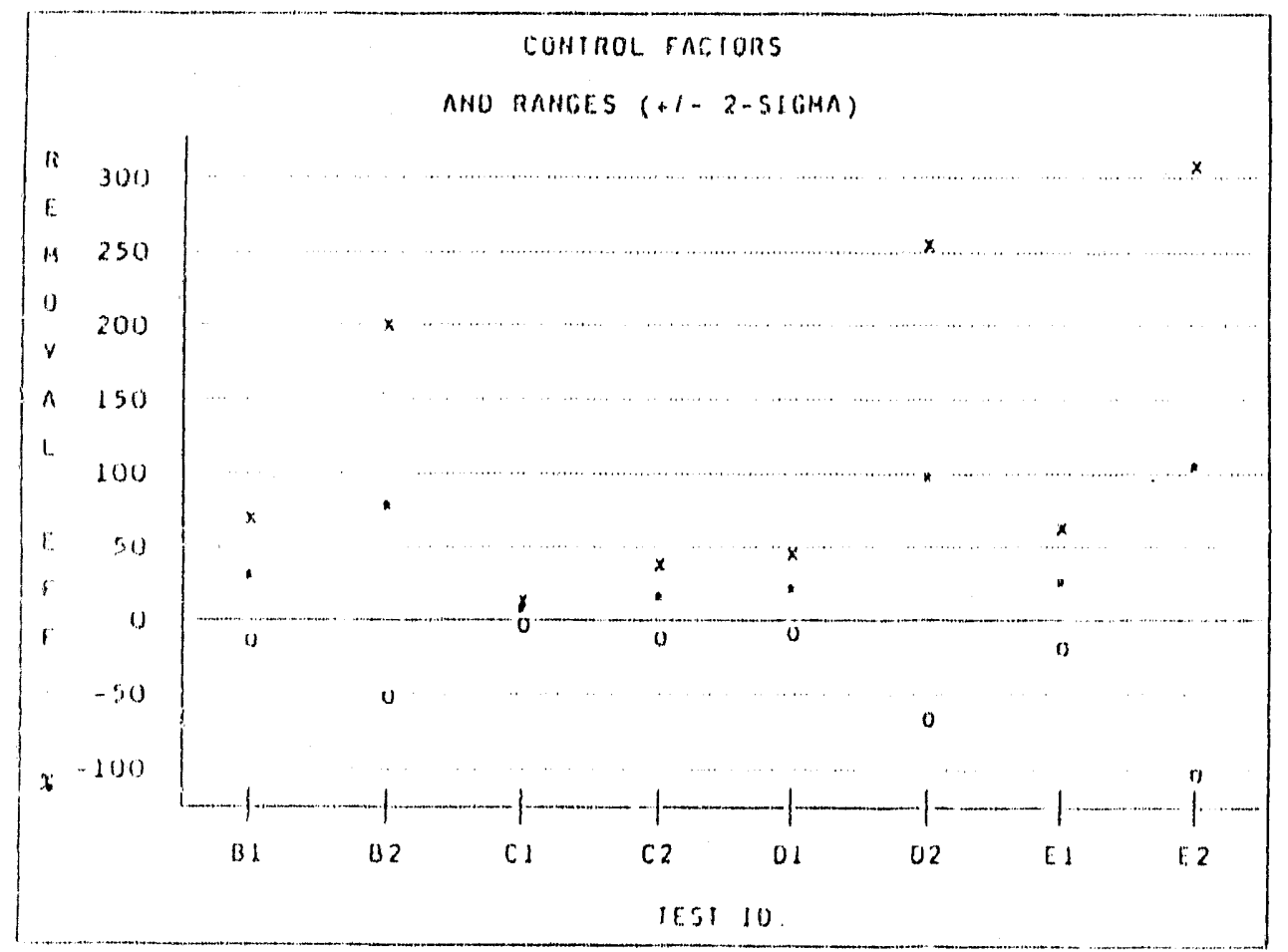

Figure 29. Control factors for all tests. 


\subsection{Data Summary}

Figures 30 and $3 i$ plot the dust control efficiency as a function of the face average velocity and the total flow rate, respectively.

Tests E1 and D1 have similar face velocities and tests E2 and D2 have similar face velocily and provided similar dust control efficiencies. However, the E test series accomplished this at a lower total flow rate with respect to the $\mathrm{D}$ test series. Therefore, partially blocking the hood entrance to increase the average face velocity was effective in reducing the flow rate requirements and thus reducing the ventilation equipment size and operating cost.

A comparison of the dust control efficiencies of test $\mathrm{C} 2$ with $\mathrm{B} 1$ indicate that flow through the lower branch helped contain the dust plume by reducing the dust that escaped the hood at similar total flow rates. Comparison of tests B2 and D1, however, provide data that conflicts with the above conclusion. If the flow through the lower branch is effective, it would be expected that the dust containment efficiency of test D1 with both upper and lower branch flow would have contained the dust better than test B2, which had flow only in the upper branch. The flow through the lower branch did, however, clear the dust from the lower portion of the funnel compared to the tests run without flow in the lower branch. The lower branch flow also reduced the height that the dust plumed up into the hood and helped clear the dust from behind the bucket.

Table 7 summarizes the results for all tests including $\mathrm{CF}, \mathrm{C}_{\mathrm{eff}}$, duct llow velocities, and face velocities. The data show that the configurations using a two-duct system eonnected in the upper hood and the lower funnel perform better than a conliguration using a single duct. The data show that the $\mathrm{CF}$ and $\mathrm{C}_{\text {eff }}$ increased as a function of duct and face velocity. For example, test $\mathrm{C} 2$ had an average measured hood face velocity of $29.6+/-5.1 \mathrm{lfpm}$. At this face velocity, test $\mathrm{C} 2$ had an average $C F$ of $15.1+/-18.1$ and $C_{e f f}$ of $87.9+/-11.7 \%$. Test $D 2$, which had a average hood face velocity of $108.3+/-15.8 \mathrm{lfpm}$, resulted in an average $\mathrm{CF}$ of $79.1+/-69.6$ and $\mathrm{C}_{\mathrm{eff}}$ of $98.55+/-1.4 \%$.

All configurations were better than the low volume misting system evaluated during previous studies. The data show that configurations $\mathrm{D} 2$ and $\mathrm{E} 2$ had the best $\mathrm{CF}$ and $\mathrm{C}_{\mathrm{eff}}$. These configurations had a $\mathrm{C}_{\mathrm{eff}}$ of over $98 \%$ when using dry soil. The best $\mathrm{C}_{\text {eff }}$ achieved by the misting system using the same soil moisture content was only $32 \%$. The worst result for the ventilation system was configuration $\mathrm{C}_{1}$ with a $\mathrm{C}_{\mathrm{eff}}$ of $69 \%$. This configuration was still over a factor of two beller than misting. 


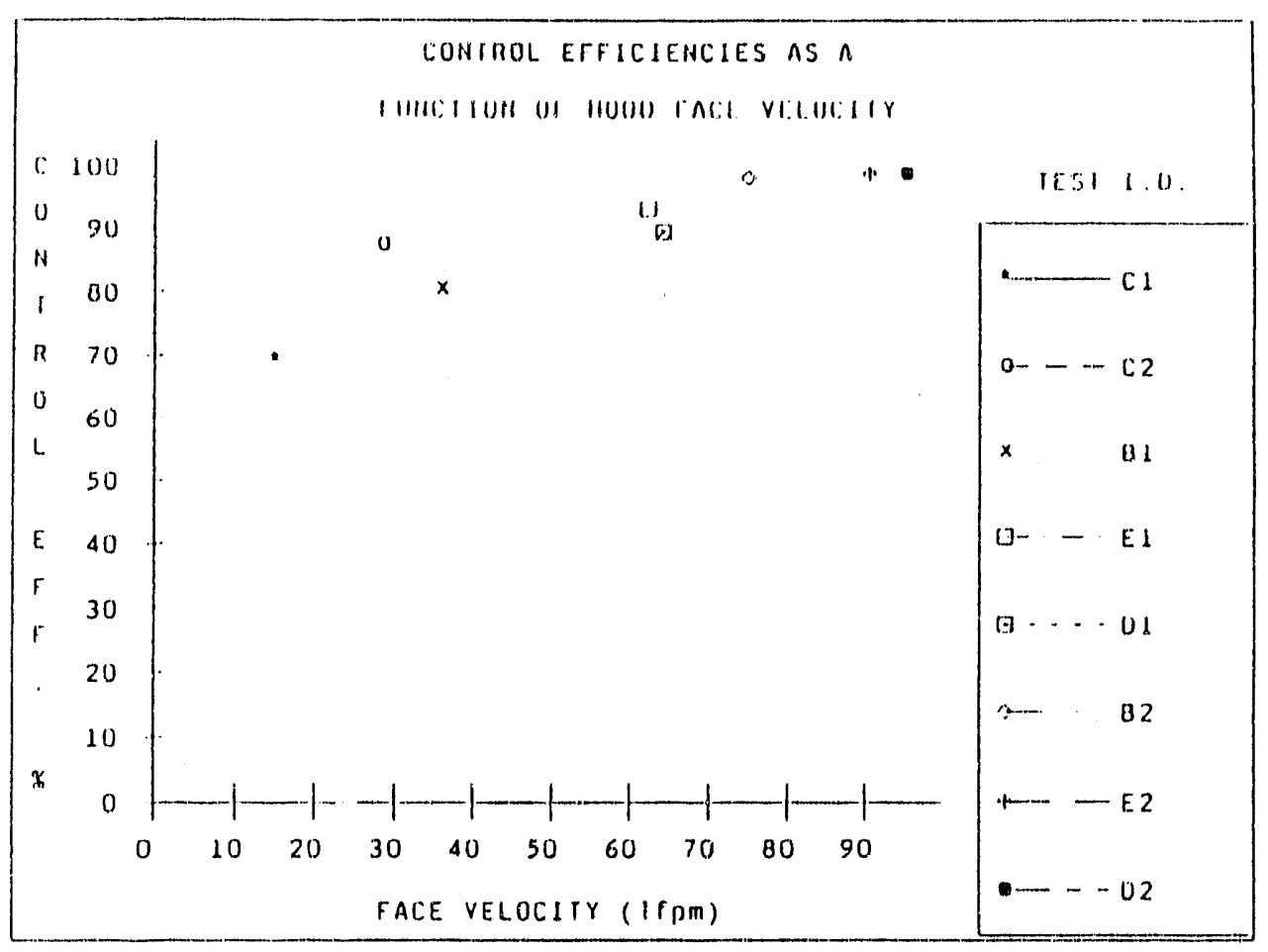

Figure 30. Control efficiency as a function of face velocity.

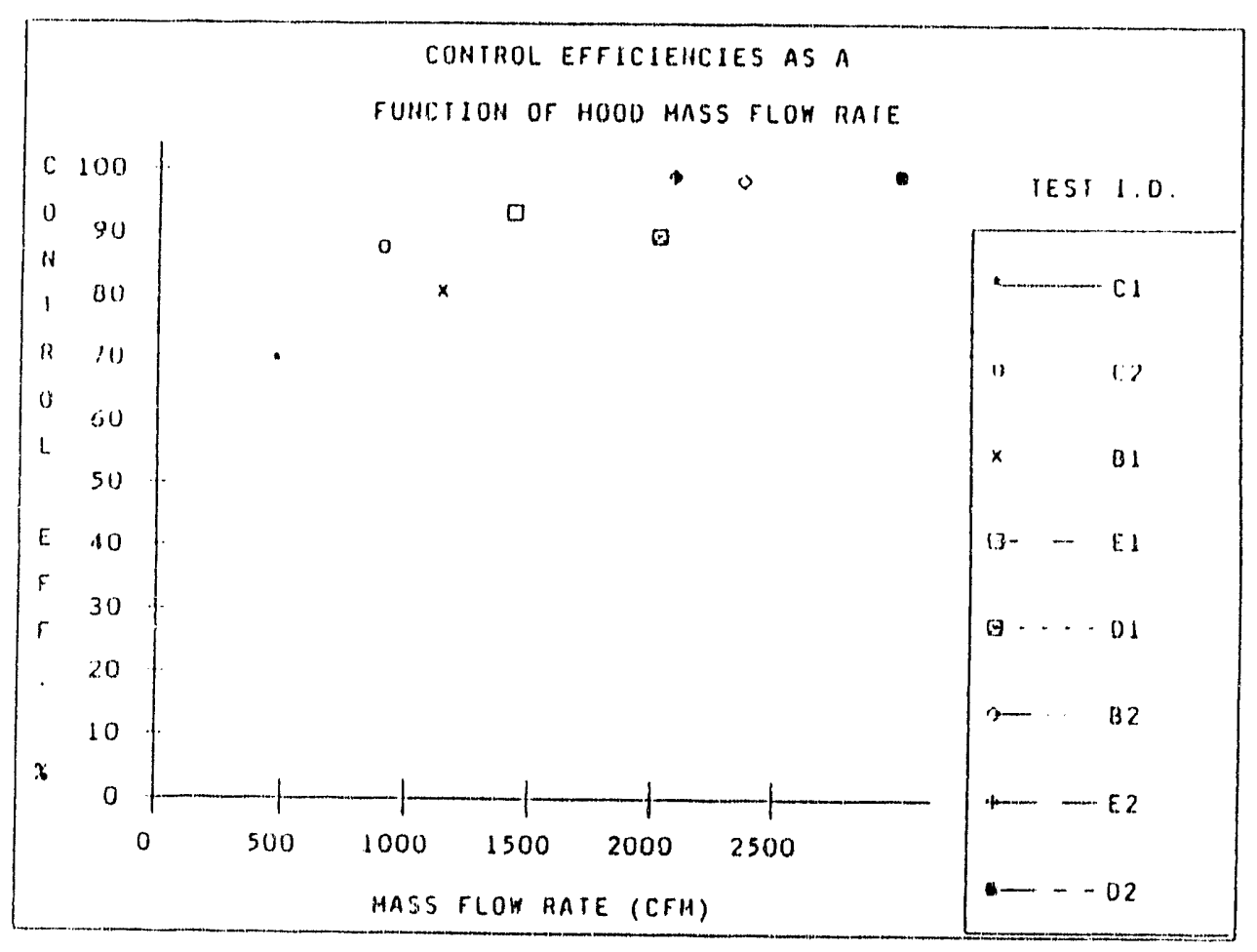

Figure 31. Control efficiency as a function of mass flow. 


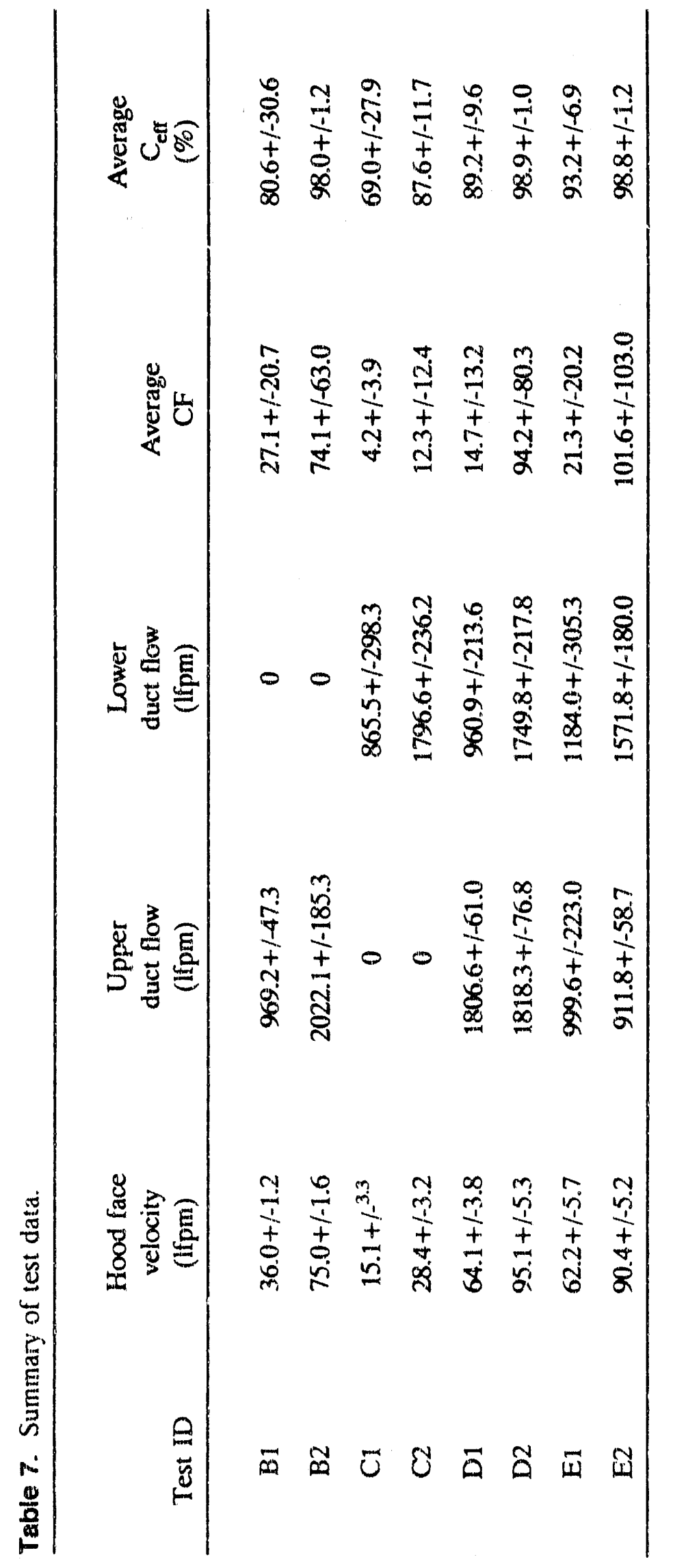




\section{CONCLUSIONS AND RECOMMENDATIONS}

The results of these tests indicate that it is feasible to use directed airflow to control fugitive dust generation during dumping operations involving a funnel to focus retrieved overburden soils or buried wastes. The use of this method will reduce the generation and spread of dusts by $98 \%$ when compared to no attempt to reduce dust spread. Possible practical applications at the INEL for such a system include:

- Removal of overburden soils at the TSA at the RWMC

- Retrieval of buried wastes in the SDA

- Accident response and remediation

- Other activities involving hazardous or radioactive wastes where it is desirable to minimize the generation of fugitive dusts or aerosolized radioactivity.

The minimum face velocity should be no less than $100 \mathrm{lfpm}$. It is recommended that a face velocity of $120 \mathrm{lfpm}$ should be obtained to meet laboratory Class A hood requirements. This face velocity should be able to obtain a control efficiency of well over $99 \%$.

It is concluded that directed airflow as a technique to control dust during dumping in a funnel is superior $t()$ using a demineralized water misting case because of the large difference in control efficiencies (98\% for the directed airflow case and $30 \%$ for the misting case). A direct comparison is not possible because of the radically different opening design and opening cross sectional area.

One of the most critical times in controlling the dust that is generated from the dumping operation is during and immediately following the dumping. The falling dirt rapidly displaces the air within the dumpster creating a pressure wave and a dust plume. The design should incorporate features to dissipate the kinetic energy of this dust plume before it reaches the enclosure (hood) exit. Mechanical features such as deflectors to absorb or direct the plume away from the exit may be employed. The dust plume may be reduced by decreasing the volume of the dump or the velocity of the dirt. Dumping the soil slowly may be an effective means to reduce the energy of the dust plume created. Another effective means to allow the energy to dissipate is to provide a large control volume (i.e., large box, funnel, and hood arrangement) that the plume would have to migrate through before it reaches the exit. These tests show that even large air velocitics could not totally control the initial plume of dust. It is also evident that small air velocities pull the dust away from the hood exit after the encrgy from the initial plume has dissipated. As a result, these types of design features need to be considered.

The downward flow through the funnel throat resulting from flow through the lower branch could not contain the initial upward plume of dust. However, a comparison of the B test series, test $\mathrm{C} 1$, and $\mathrm{C} 2$ showed that the lower branch flow was effective in reducing the height that the plume rose up the funnel as the flow was increased. In addition, with increasing flow rates in the lower branch, the faster the dust cleared from the lower portion of the funnel. 
Another critical time for controlling the dust from escaping the hood is during the removal of the bucket. The outward motion of the bucket could pull dust with it, particularly in the stagnant flow region within the bucket. To reduce the dust removed as the bucket is removed, it is necessary to reduce the dust in the hood region prior to removal of the bucket. This is best achieved by minimizing the stagnant regions within the hood to allow the ventilation system to remove the dust prior to removal of the bucket. It was observed during the B test series (with only upper branch flow) that dust remained within and behind the bucket for an extended period of time. The test series with flow through the lower branch reduced the dust clearout time around the bucket by reducing the stagnant air regions.

The disadvantage of the flow through the lower branch of ducting was the increased amount of dust that was pulled into the ventilation system. This resulted since the flow through the lower branch was around the bottom of the funnel throat near the soil and around the area of high dust concentrations during the dump operation. Therefore, the amount of flow through the lower branch must be weighed against the increase in demands on the air cleaning devices and the fan as a result of the increased system flow resistance.

The information obtained from these experiments should be used as an additional source of information in designing a local ventilation system to control contaminants. For example, References 5 and 6 provide guidance on the design of local ventilation systems for contamination control. Reference 5 provides hundreds of hood illustrations for specific operations as guides for design purposes. In many cases, the illustrations are taken from actual installations of successful local ventilation systems. It is recommended that these types of information also be consulted and design experience be factored into a ventilation system design to a hieve overall balanced design with design features, sufficient air volumes, and air velocities to provide the required level of air contaminant control for a particular operation without oversizing the local ventilation system.

The following recommendations can be made based on these results:

- A system will need to be engineered to create and maintain an adequate seal between the funnel and box during dumping operations

- Bag houses will have to be installed in front of the HEPA filters in order to increase the useful life of the HEPA and minimize filter change outs

- A two-duct system should be utilized by creating airflow in the upper hood area and in the lower funnel area near the box funnel junction

- The lower duct should be attached to the centerline of the funnel to distribute the airllow evenly. 


\section{REFERENCES}

1. M. R. Winberg, R. J. Pawelko, N. C. Jacobs, D. N. Thompson, Engineering Scale Dust Control Experiments, EGG-WTD-9387, December 1990.

2. S. W. Duce, M. R. Winberg, A. L. Freeman, Basic Radiological Studies Contamination Control Experiments, EGG-WM-8724, September 1989.

3. M. R. Winberg, Test Plan for FY-91 Dust Control Studies, EGG-WTD-9553, March 1991.

4. M. R. Winberg, Amendment to EGG-WTD-9553 Test Plan for FY-91 Dust Control Experiments, ST-PHY-92-033, April 1992.

5. American Conference of Governmental Hygienist (ACGIH), Industrial Ventilation, A Manual of Recommended Practice, Michigan: Edwards Brothers, Inc., $18^{\text {th }}$ edition, 1984.

6. Henry McDermott, Handbook of Ventilation for Contamination Control, Michigan: Ann Arbor Science Publishers, Inc. 
4

Appendix A

Calculational Methods 


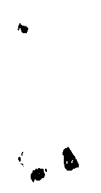

A-2 


\section{Appendix A}

\section{Calculational Methods}

All initial data used to make the calculations to determine the results contained in this report is found in Appendix A of this report. For each test sequence a dust control factor (CF) and dust control efficiency $\left(C_{\text {erf }}\right)$ was calculated, where:

$\mathrm{CF}=\mathrm{C}_{\mathrm{n}} / \mathrm{C}_{\mathrm{v}}$

$\mathrm{C}_{\mathrm{eff}} \%=1-\left[\mathrm{C}_{\mathrm{v}} / \mathrm{C}_{\mathrm{n}}\right] * 100$

where

$\mathrm{C}_{\mathrm{n}}=$ the average dust concentration at a particular sampler location in $\mathrm{g} / \mathrm{l}$ with no ventilation system in operation

$\mathrm{C}_{\mathrm{v}}=$ the average dust concentration at a particular sampler location in $\mathrm{g} / \mathrm{l}$ for all test sequences with the ventilation system in operation.

All averages and standard deviations for each sampler location were calculated by using the following equations:

$A V G=\left(\Sigma C_{i}\right) / N$ (Note: this value was used as $C_{n}$ or $C_{v}$ depending on the test sequence)

$S T D=\operatorname{SQRT}\left[\Sigma\left(C_{i}-A V G\right)^{\wedge} 2 /(N-1)\right]$

where $C_{i}=\quad \begin{aligned} & \text { The concentration in } g / l \text { for each sample location for each test sequence } \\ & \text { performed }\end{aligned}$

$\mathrm{N}=$ The number of times each test was run.

The standard deviation for the control factor and control efficiency is calculated as:

$\left.\mathrm{STD}_{\mathrm{Cl}}=\mathrm{CF} * \mathrm{SQRT} \mid\left(\sigma_{\mathrm{Cn}} / \mathrm{C}_{\mathrm{n}}\right)^{2}+\left(\sigma_{\mathrm{Cv}} / \mathrm{C}_{\mathrm{v}}\right)^{2}\right\}$

$\mathrm{STD}_{\mathrm{RuIr}}=\left(100-\mathrm{C}_{\mathrm{urn}} * \mathrm{SQRT} \mid \sigma_{\mathrm{Ch}_{\mathrm{n}}} / \mathrm{Cn}\right) 2+\left(\sigma_{\mathrm{Cv}} / \mathrm{C}_{\mathrm{v}}\right)^{2} \mid$

where

$\sigma_{C n}=$ The standard deviation of the average dust concentration at a particular sampling location with no ventilation system in operation

$\sigma_{C v}=$ The standard deviation of the average dust concentration at a particular sampling location with the ventilation system in operation in its various configurations. 

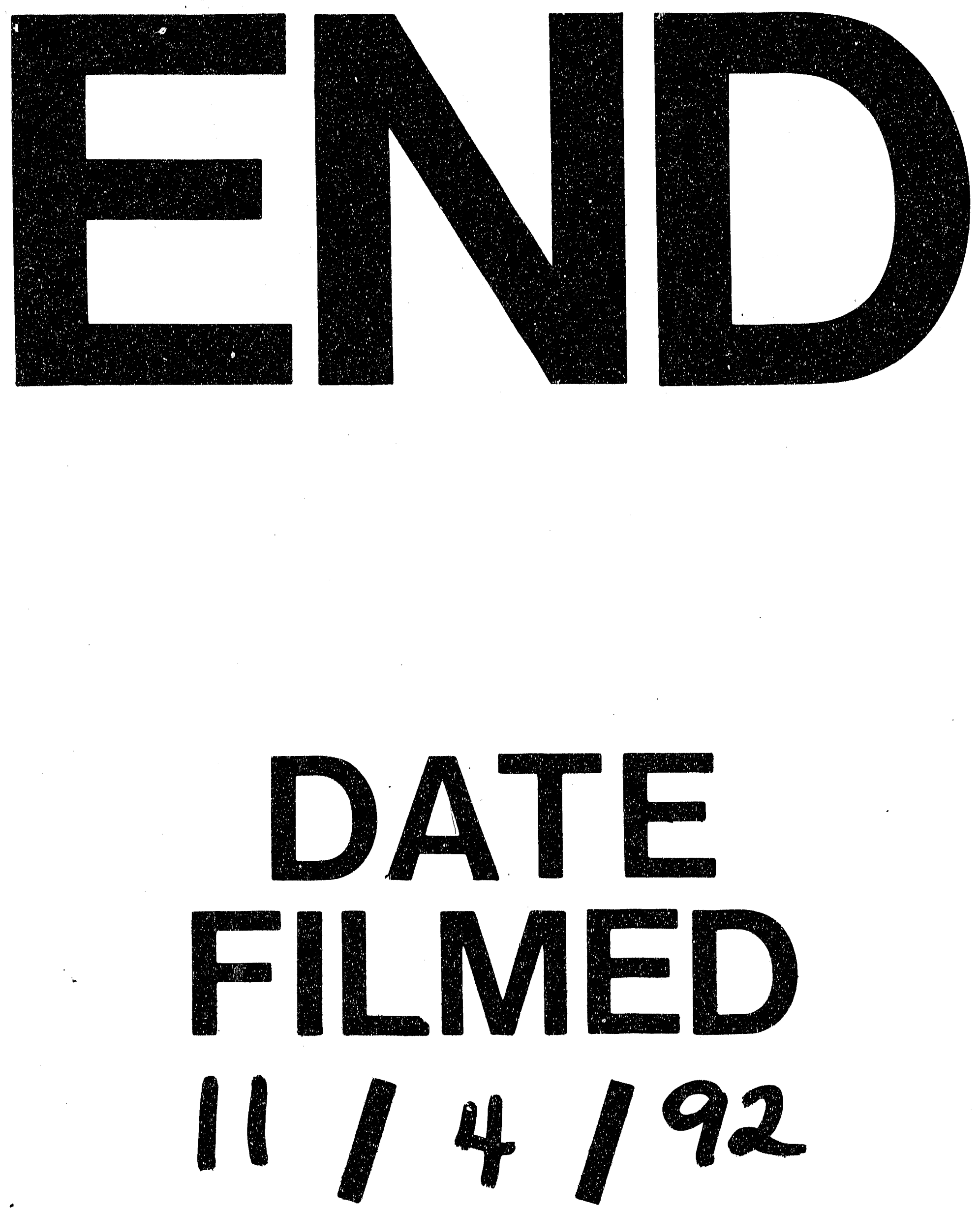

$=$ 
